\title{
A Comparative Study of the Native Oxide on 316L Stainless Steel by XPS and ToF-SIMS
}

Running title: Study of the Native Oxide on 316L Stainless Steel

Running Authors: Tardio et al.

\section{Sabrina Tardiob)}

Department of Mechanical Engineering Sciences, University of Surrey, Guildford, Surrey, GU2 7XH, U.K.

\section{Marie-Laure Abel}

Department of Mechanical Engineering Sciences, University of Surrey, Guildford, Surrey, GU2 7XH, U.K.

$$
\text { Robert H. Carr }
$$

Huntsman PU, Everslaan 45, B-3078 Everberg, Belgium

\section{James E. Castlea)}

Department of Mechanical Engineering Sciences, University of Surrey, Guildford, Surrey, GU2 7XH, U.K.

\section{John F. Watts}

Department of Mechanical Engineering Sciences, University of Surrey, Guildford, Surrey, GU2 7XH, U.K.

a)American Vacuum Society member.

b)Electronic mail: s.tardio@surrey.ac.uk

The very thin native oxide film on stainless steel, of the order of $2 \mathrm{~nm}$, is known to be readily modified by immersion in aqueous media. In this paper, XPS and ToF-SIMS are employed to investigate the nature of the air-formed film and modification after water emmersion.

The film is described in terms of oxide, hydroxide and water content. The preferential dissolution of iron is shown to occur on immersion. It is shown that a water absorbed layer and a hydroxide layer are present above the oxide-like passive film. The concentrations of water and hydroxide appear to be higher in the case of exposure to water. A secure method 
for the peak fitting of Fe2p and Cr2p XPS spectra of such films on their metallic substrates is described. The importance of XPS survey spectra is underlined and the feasibility of $\mathrm{C}_{60}{ }^{+}$ SIMS depth profiling of a thin oxide layer is shown.

\section{INTRODUCTION}

AISI 316L is an austenitic stainless steel which is widely used in applications that require a degree of resistance to crevice and/or pitting corrosion. The L identifier of $316 \mathrm{~L}$ indicates lower carbon content than the standard 316 grade, a characteristic which reduces the susceptibility to sensitization (grain boundary carbide precipitation) and for this reason it is widely used in heavy gauge welded components. The typical composition of $316 \mathrm{~L}$ steel is given in Table I.

Table I: Composition of AISI 316L stainless steel. Values are the maximum allowable unless a range is given which indicates minimum and maximum values.

\begin{tabular}{ccccccccccc}
\hline \hline \multicolumn{10}{c}{ Composition/Weight \% } \\
\hline $\mathbf{C}$ & $\mathbf{C r}$ & $\mathbf{N i}$ & $\mathbf{M o}$ & $\mathbf{M n}$ & $\mathbf{S i}$ & $\mathbf{P}$ & $\mathbf{S}$ & $\mathbf{N}$ & $\mathbf{F e}$ \\
0.03 & $16.00-18.00$ & $10.00-14.00$ & $2.00-3.00$ & 2.00 & 0.75 & 0.05 & 0.03 & 0.10 & balance \\
\hline \hline
\end{tabular}

The corrosion resistance of stainless steel is a result of the presence of a thin oxide layer on its surface. The passivation of stainless steel takes place in atmospheric conditions which yields a film that is self-healing on localised damage. The oxide, naturally formed in the atmosphere, is generally referred to as the native oxide and it is affected by environmental factors and, for this reason, different methods are often employed to modify the oxide layer to make it suitable for particular applications. For example modifications of the 316L steel surface, to facilitate the deposition of supports for catalysts, were made by ensuring large surface areas where nickel oxide is predominant ${ }^{1}$ or by forming chromium oxide films by immersion in a chromium electrolyte ${ }^{2}$. Sometimes it is important to see how the surface is 
modified during operating conditions in order to, understand fouling or corrosion mechanisms. For instance there are works reporting on the growth of the oxide on the $316 \mathrm{~L}$ stainless steel in high-temperature water, mimicking the conditions of a pressured water reactor $^{3}$, and on the effect of welding, which provokes discoloration in the heat-affected zone of the steel which ultimately leads to corrosion ${ }^{4}$. As austenitic steels are among the most employed metals in biomedical applications, many studies concern with the improvment of the material from a biocompatibility as well as a stability of the oxide point of view ${ }^{5,6}$.

This steel is also widely used as a substrate for adhesion; it is one of the "technological surfaces" on which organic coatings are applied. In this context, differences in the chemistry of the surface, as a consequence of different treatments or cleaning processes, will influence the degree and modality of interaction of the adhesives with this metal ${ }^{7,8}$. Many works present an overview on the passive film of steel ${ }^{9}$, and many involve XPS ${ }^{10}$, but few have compared the composition of the passive film in its air-formed and after water exposure and show a correct XPS peak fitting of transition metals or use all the information available by XPS. To modify the steel oxide layer or to understand how the environment influences it, it is important to know the starting point. For these reasons in this paper attention is focused on the composition of the native oxide and changes in its chemistry brought about by water exposure. XPS and ToF-SIMS were employed to investigate the nature of the native oxide on 316L stainless steel and establish how it is modified by immersion in water. As conventional ion bombardment will promote the solid-state redox reaction between iron oxide and chromium metal, in-depth information has been obtained by angle resolved XPS (ARXPS) as well as ToF-SIMS depth profiling using a $\mathrm{C}_{60}{ }^{+}$cluster source. This work takes advantage of the complementarity of these two techniques for the analysis of thin oxide layers on metals and shows the usefulness of the observation of the survey spectrum prior more detailed analysis of high resolution spectra. 


\section{EXPERIMENTAL}

\section{a) Sample preparation}

Stainless steel 316L mirror finished sheets were cut into $10 \times 10 \mathrm{~mm}^{2}$ coupons. These coupons were, without any previous treatment, etched free of oxide and other extraneous material in the XPS spectrometer (Thermo Scientific Theta Probe spectrometer). This was obtained by using a Thermo EX05 argon ion gun (ion energy: $3 \mathrm{kV}$, raster area: $2.5 \mathrm{~mm}$ and sample current: $2 \mu \mathrm{A}$ ). The sample was etched until the oxygen signal reached its minimum of intensity (after around $1600 \mathrm{~s}$ sputter time) and after further etching the signal doesn`t show any changes (Even in ultra-high vacuum the metallic chromium will getter some of the remaining oxygen in the chamber) The samples were then exposed, at the same time, to air and water at ambient temperature (humidity in the lab is of circa 40\%). Analyses were carried out after exposure to laboratory air for 30 minutes, and air exposure followed by immersion in high purity water for a further 30 minutes.

\section{b) XPS analysis}

\section{1) Acquisition}

XPS analyses were carried out using a Thermo Scientific Theta Probe spectrometer. The survey spectra were acquired in the constant analyser mode at a pass-energy of $300 \mathrm{eV}$ with a step size of $0.4 \mathrm{eV}$, the high resolution spectra at a pass-energy of $50 \mathrm{eV}$ with step size of $0.2 \mathrm{eV}$. A monochromated Al K $\alpha$ X-ray was employed $(\mathrm{h} v=1486.68 \mathrm{eV})$. Parallel angle resolved XPS (PARXPS with 16 angles between $25^{\circ}$ and $81^{\circ}$ ) was used in order to obtain in depth information for the study of the native oxide layer on stainless steel. For integral spectra $\theta$ is taken as $53^{\circ}$ which represents the mid-point of an acceptance angle of $\pm 28^{\circ}$. 
Spectra were acquired and initially processed using the instrument manufacturer's software (Avantage V4.45).

\section{2) Curve fitting}

The high resolution XPS spectra were fitted using the software NEWGOOGLY developed by Proctor ${ }^{11}$ which employs a background function plus a peak function. This was necessary for reasons that will become apparent later in this paper, but the essential feature of NEWGOOGLY is the ability to add individual energy loss tails to each component in the $\mathrm{Fe} 2 \mathrm{p}$ or $\mathrm{Cr} 2 \mathrm{p}$ spectra. A serious disadvantage of all original equipment manufacturer (OEM) software, and most widely available third party systems, is the need to remove a global energy loss background from the spectrum prior to peak fitting. In the case of the $3 \mathrm{~d}$ transition metals, with their steeply rising background signal, this can lead to serious errors in peak fitting. The peak shape used in NEWGOOGLY, and all other XPS peak fitting software, is a Voigt function (Gaussian/Lorentzian mix) defined by the binding energy maximum, peak widths, and the G/L ratio. The background consists of a Shirley function which has been multiplied with a polynomial P shown in Eq. 1, in order to produce a background tail.

$$
P=\kappa+B_{1}\left(E-E_{0}\right)
$$

where $B_{1}$ is the slope parameter of the tail and $\kappa$ is the Kappa parameter (a shape parameter which defines the intensity of the intrinsic losses):

$$
\kappa=h / A,(2)
$$

where $\mathrm{h}$ is the maximum value of the linear background projected to the peak centre and $\mathrm{A}$ is the Voigt $(\mathrm{G} / \mathrm{L})$ peak area ${ }^{12,13,14}$. 


\section{c) ToF-SIMS analysis}

A TOF.SIMS5 (ION-TOF GmbH, Münster, Germany) system was employed for ToFSIMS analyses. Static SIMS condition (ion dose $<1 \times 10^{13}$ ions $\mathrm{cm}^{-2}$ ) were employed using a $25 \mathrm{keV} \mathrm{Bi}_{3}{ }^{+}$primary ion beam, with $9.5 \mathrm{keV}$ extractor voltage, rastered over an area of $100 \mathrm{x}$ $100 \mu \mathrm{m}$. Both positive and negative SIMS spectra were acquired in high resolution (bunched) mode over a mass range of $1-850 \mathrm{u}$. Sputter profiling was carried out using a $10 \mathrm{keV} \mathrm{C}_{60}{ }^{+}$ion source rastered over an area of $400 \times 400 \mu \mathrm{m}$, with a current of $2 \mathrm{nA}$, operating in the interlaced mode. Spectral acquisition and processing was achieved using ION-TOF GmbH software.

\section{DATA PROCESSING AND RESULTS}

\section{a) XPS data}

\section{1) Survey spectra data}

The XPS survey spectrum of the air-exposed sample is shown in Figure 1: primary peaks are identified, revealing, the elements present in the steel together with oxygen and carbon. The oxygen signal is produced from the thin oxide layer present on the surface of the steel. The carbon signal is produced from a surface layer of adsorbed organic contamination. The argon peak indicates the presence of ions implanted during the sputtering pretreatment of the sample. Figure 2 shows the survey spectrum after water exposure. 


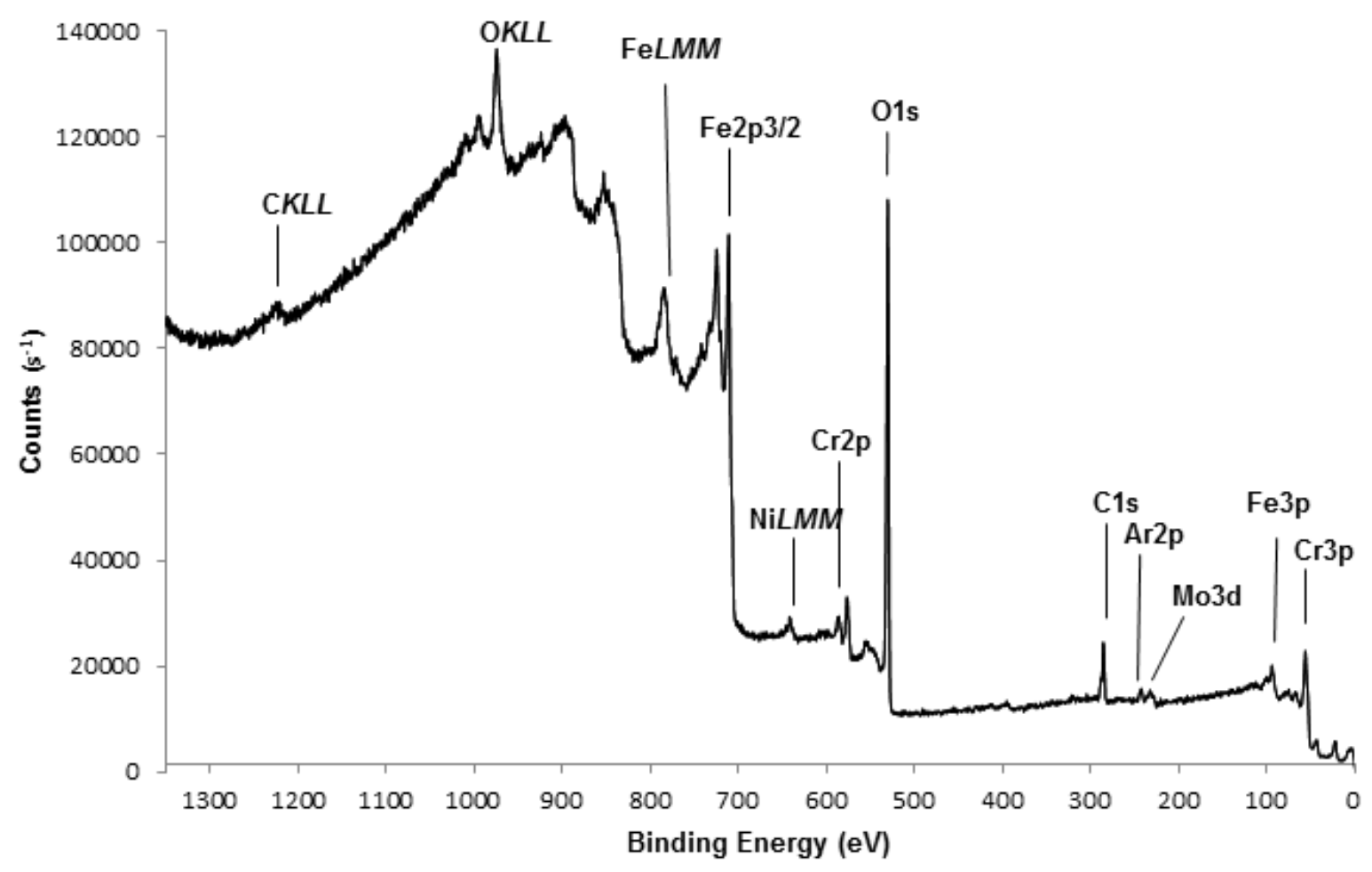

Figure 1: XPS survey spectrum of air exposed stainless steel.

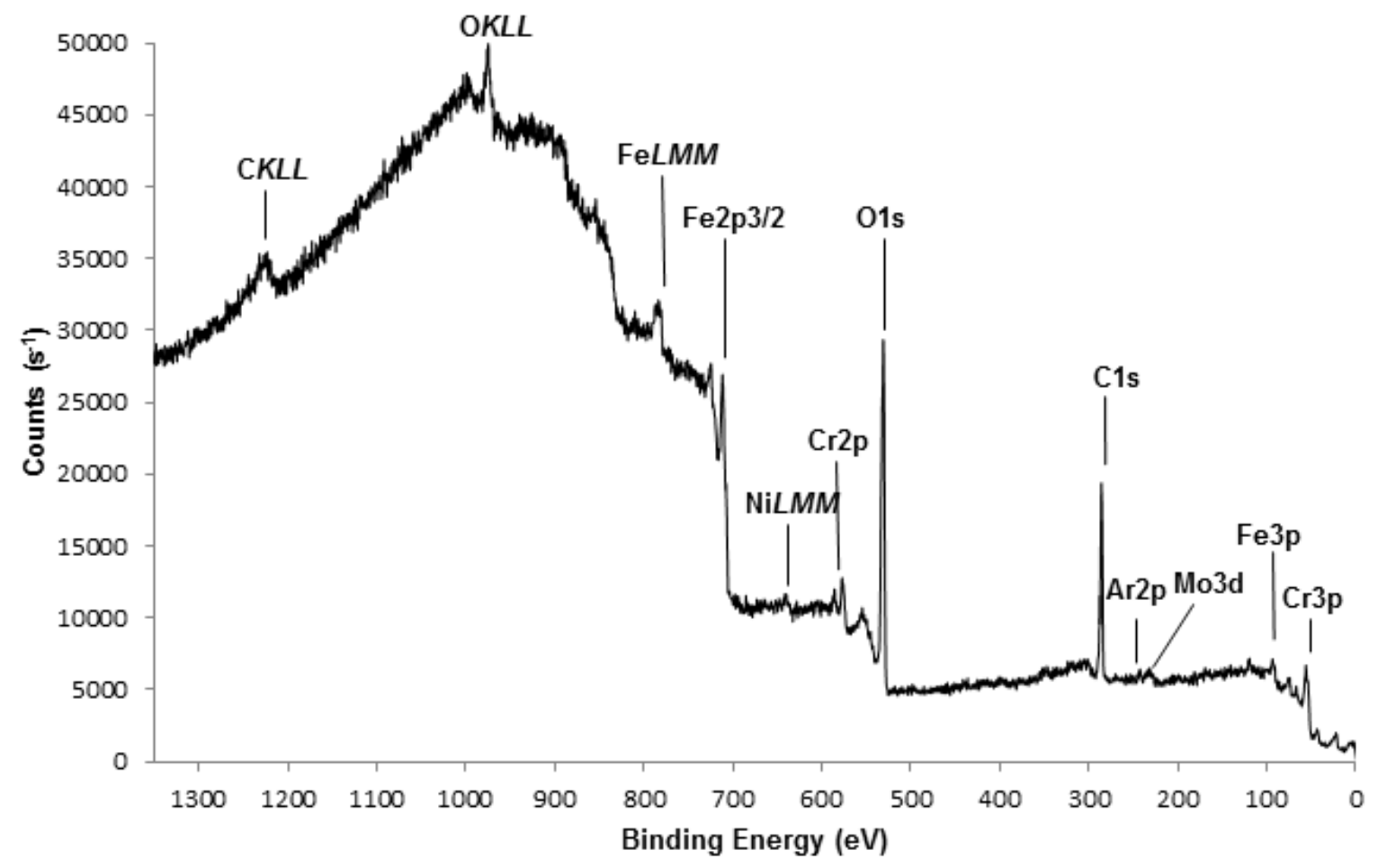

Figure 2: XPS survey spectrum of water exposed stainless steel.

The survey spectra are an important and underutilized resource, with which is possible to obtain much information about a sample. In this case they provide a perspective 
on the structure of oxides on alloys, prior to more extensive curve fitting of individual high resolution spectra. For most passive and native oxides and alloys, the XPS analysis provides information about the oxide composition with only a minor contribution from the underlying metallic phase. The actual depth sampled does vary significantly from one end of the XPS spectrum to the other, according to the dependence of its intensity on the kinetic energy of the emitted electron. As an example, in Figure 3 we have plotted the attenuation, with depth, of the signal intensity using the Effective Attenuation Length ${ }^{15}$ (EAL) for the Fe3p (2.3nm) and Fe2p (1.2nm) peaks (kinetic energies $1387 \mathrm{eV}$ and $777 \mathrm{eV}$ ) respectively: the electron takeoff angle was taken to be $53^{\circ}$, as used throughout the present work. In this diagram, the attenuation curve has been matched to its mirror image so that the area between the curves, for any given interval of depth, represents the contribution from that region to the overall signal intensity. The benefit of this diagram is that it shows, at a glance, the much increased contribution made by the metal phase, to the overall signal. 

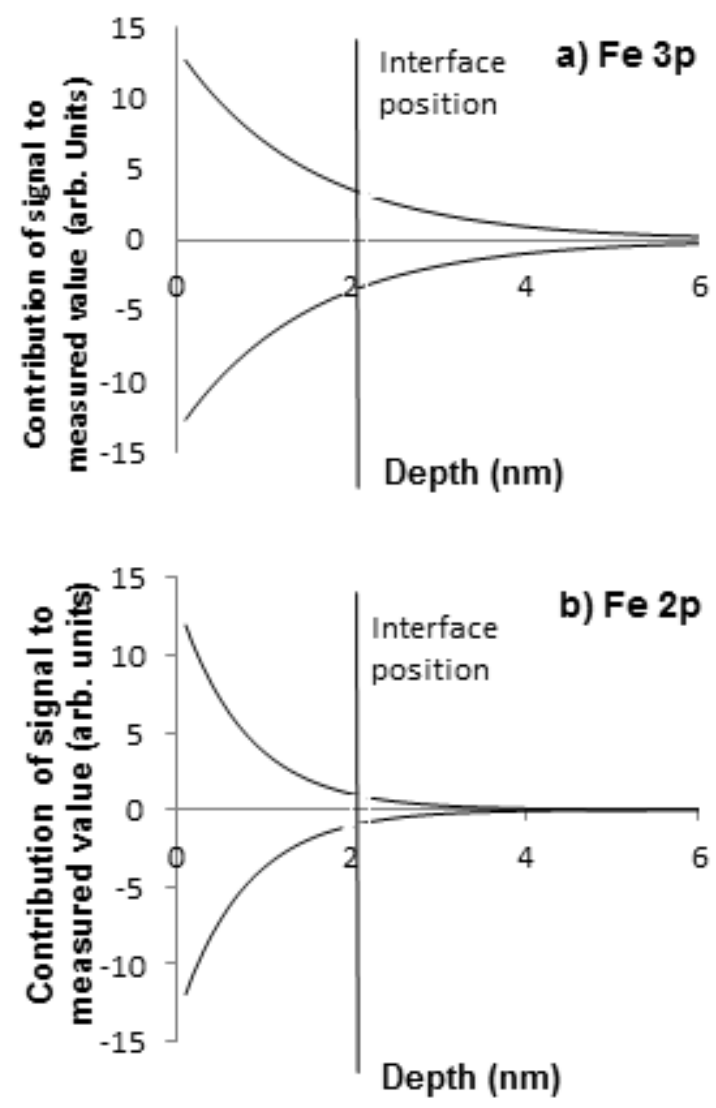

Figure 3: The contribution of signal to the XPS analysis using data for iron. The interface position is that obtained in air.

In the present case, the $3 p$ peaks of iron, chromium and nickel (kinetic energy $~ 1400$ eV) sample a greater depth than the 2 p peaks (kinetic energy $\sim 700 \mathrm{ev}$ ) of the same elements. Castle ${ }^{16}$ has described a sequence by which this information can be used in a systematic manner and this starts with quantification of both $2 p$ and $3 p$ peaks intensities, as shown in Table II, for the two conditions of exposure; i.e. in air and in water. 
Table II: Concentration derived from the survey spectra.

\begin{tabular}{|c|c|c|c|c|c|c|}
\hline Air & $\mathrm{C}(1 \mathrm{~s}) \%$ & $\mathrm{O}(1 \mathrm{~s}) \%$ & $\mathrm{Fe} \%$ & $\mathrm{Cr} \%$ & $\mathrm{Ni \%}$ & $\operatorname{Mo}(3 d) \%$ \\
\hline $2 p$ & 18.5 & 49.0 & 27.0 & 3.0 & 2.0 & 0.5 \\
\hline $3 p$ & 20.5 & 54.5 & 18.5 & 4.0 & 2.0 & 0.5 \\
\hline Water & $\mathrm{C}(1 \mathrm{~s}) \%$ & $\mathbf{O}(1 \mathrm{~s}) \%$ & $\mathrm{Fe} \%$ & $\mathrm{Cr} \%$ & $\mathrm{Ni \%}$ & $\operatorname{Mo}(3 d) \%$ \\
\hline $2 p$ & 44.6 & 39.4 & 10.9 & 2.6 & 1.8 & 0.7 \\
\hline $3 p$ & 43.2 & 38.2 & 11.3 & 2.6 & 4.0 & 0.7 \\
\hline
\end{tabular}

Carbon from a contamination film is included in this first analysis. However, the C1s signal can be used to estimate the thickness of the surface film which will have attenuated the $2 p$ and $3 p$ peaks to differing extents, depending on their kinetic energies. The procedure was first elaborated by Castle and Baker ${ }^{17}$ and confirmed in measurements made by Smith ${ }^{18}$; a more recent description can be found in reference ${ }^{16}$. An automated form of this procedure was used and described by Baer, Englehard and Lea ${ }^{19}$. The thickness of the contamination layer is estimated as:

$$
D_{\text {Cont. }}=-L_{C 1 s} \cos \theta(1-[C] / 100) \text {, }
$$

where $\mathrm{L}_{\mathrm{Cls}}$ is the EAL of the $\mathrm{C} 1 \mathrm{~s}$ electron, $\theta$ is the take-off angle relative to the sample normal and $[\mathrm{C}]$ is the concentration of carbon expressed as an atom fraction. Having obtained a value for $\mathrm{D}_{\text {Cont. }}$, the intensity for each peak of interest can be corrected for attenuation using the relationship: 


$$
I_{\text {corrected }}=I_{\text {observed }} \exp \left(D_{\text {cont. }} / L_{z} \cos \theta\right)
$$

where $L_{z}$ is the EAL for each peak of interest. Having obtained this set of values, the carbon concentration can be set to zero and the analysis renormalized to atomic percentage. This correction has been applied to the values shown in Table II with the results given in Table III together with the estimated thickness of the contamination layer that was used for the correction. A first step in making use of the differing analysis depths of the $2 p$ and $3 p$ peaks is to calculate their concentrations relative to the total of all metal elements or cations within the XPS analysis volume. i.e. the values in Table III, can be expressed in the following form:

$$
Z 2 p(\text { rel.conc. })=Z 2 p \% /(F e 2 p \%+C r 2 p \%+N i 2 p \%+M o 3 d \%)
$$

where $\mathrm{Z}$ takes the value, in turn, for each of the elements in the denominator. These values can then be related to the concentration of the elements in the alloy (as atomic percentage) to give a factor $(\mathrm{F})$ indicating the enrichment or depletion of the given element. As an example, the factor for iron becomes:

$$
F_{F e}=(F e 2 p \%+C r 2 p \%+N i 2 p \%+M o 3 d \%) /(\mathrm{Fe} / \mathrm{Fe}+\mathrm{Cr}+\mathrm{Ni}+\mathrm{Mo})
$$

This factor differs slightly from the enrichment factors used extensively by Asami et al. ${ }^{20,21}$ and by Castle and Qiu ${ }^{22}$, which are based on oxide compositions determined after curve fitting to eliminate the metallic component. The factors determined above relate to the total signal, as acquired in the XPS analysis. This is a good approximation, considering, as it will be seen later in this report that the cationic area constitute around the $90 \%$ of the total metallic peak area. 
Table III: Corrected concentration and related enrichment factors derived from the survey scans and enrichment factors. Cont. d. is the thickness of the contamination layer.

\begin{tabular}{l|llllll}
\hline \hline Air & Fe & $\mathbf{C r}$ & $\mathbf{N i}$ & $\mathbf{M o}(\mathbf{3 d})$ & $\mathbf{O ( 1 s )}$ & Cont. d. (nm) \\
\hline 2p\% & 33.5 & 3.7 & 2.4 & 0.6 & 59.8 & 0.4 \\
$\mathbf{3 p \%}$ & 22.9 & 4.9 & 2.5 & 0.6 & 69.0 & \\
$\mathbf{F}$ 2p & 1.21 & 0.46 & 0.61 & 1.20 & & \\
F3p & 1.08 & 0.80 & 0.82 & 1.18 & & \\
\hline Water & Fe & $\mathbf{C r}$ & $\mathbf{N i}$ & $\mathbf{M o}(\mathbf{3 d})$ & $\mathbf{O ( 1 s )}$ & Cont. d. (nm) \\
\hline 2p\% & 20.4 & 4.7 & 3.0 & 1.2 & 70.7 & 1.2 \\
$\mathbf{3 p \%}$ & 20.7 & 4.6 & 6.6 & 1.2 & 66.9 & \\
F2p & 1.08 & 0.80 & 1.07 & 2.40 & & \\
F3p & 0.88 & 0.70 & 2.22 & 2.25 & & \\
\hline \hline
\end{tabular}

Analysis of film produced upon air exposure showed significant differences between the quantification made using the $2 p$ peaks and those made using the $3 p$ peaks. These immediately indicate that the composition varies with the kinetic energy, i.e. that it varies with analysis depth. Recalling that the analysis depth is greater for the $3 p$ peaks this indicated that iron has an enhanced concentration in the oxide films. For chromium the reverse is true and nickel behaves like chromium. For Molybdenum the only observable peak is the $3 \mathrm{~d}$, therefore a difference in enrichment factor cannot be shown.

The enrichment factor gives a measure of the difference of those compositions relative to the nominal composition of the steel. Iron has about $20 \%$ higher concentration near the outer surface whereas chromium is reduced to about half the concentration in the alloy over this analysis range. 
Turning now to the set of data obtained after the brief exposure to water, it is possible to see a striking change in the observed concentrations. The chromium concentration grows to be the $80 \%$ of its alloy concentration and iron, enriched before, now shows relatively little enrichment $(\mathrm{F} 2 \mathrm{p}=1.08)$ compared to the alloy composition. Also in this case the enrichment factors confirm that there are gradients of composition within the depth accessed by XPS in the same direction compared with the air exposed surface.

The depth information from the different peaks of iron, nickel and chromium can be used to provide an estimate of the near-surface concentration gradients. The XPS concentration is the average value obtained when the composition gradient is integrated according to the well-known exponential function. It follows that the XPS value will be equal to the actual value at some depth beneath the surface. These depths will be different for the values derived from the $2 \mathrm{p}$ and the $3 \mathrm{p}$ peaks, respectively, and thus, if they were known, could be used to estimate the value and direction of any concentration gradients. Such information is most often obtained by use of angle resolved spectra to examine the intensity variation of a single peak. In this context, Seah et al. ${ }^{23}$ have shown that when the XPS concentration is placed at a depth of $0.35 t$, where $t$ is the thickness of a layer containing the element concerned, then the observed concentration is almost invariant with angle. To provide an estimate of the concentration gradients from the $2 p$ and $3 p$ peaks, we adopt this "magic depth" as the point at which the XPS concentration equals the actual concentration. The thickness of the layer of interest, $t$, can be taken as the value $3 \mathrm{~L} \cos \theta$, where $\mathrm{L}$ takes the value appropriate to the kinetic energy of the given peak and $\theta$ is the take-off angle of the photoelectrons normal to the sample surface: this depth, although arbitrary; is the effective sampling depth for XPS. The magic depth thus becomes $1.05 L \cos \theta$. Values of $L$, corresponding to the escape of electrons from the $2 p$ and $3 p$ level in the oxide, can be obtained $^{15}$, and the concentration of each element in Table III can be plotted as shown in 
Figure 4. Since the gradients are based on only two data points, they cannot be used to imply the presence of true gradients: a stepwise distribution is still possible. The gradients do however indicate the highly localized nature of the surface enrichment in a graphic manner. Having the two data points, the line through them is easily extended forward to the metal phase and backwards to the surface. If the forward extrapolation is terminated when the extrapolated concentration of the given element equals that found in the metal, then the depth at which this occurs gives an estimate of the overall thickness of the altered layer (mainly oxide but there might be a change in the metal composition at the interface because of element depletion or enrichment). The thickness of the surface oxide layer derived by this method (using the air exposed sample as an example) is about $2 \mathrm{~nm}$, as expected.

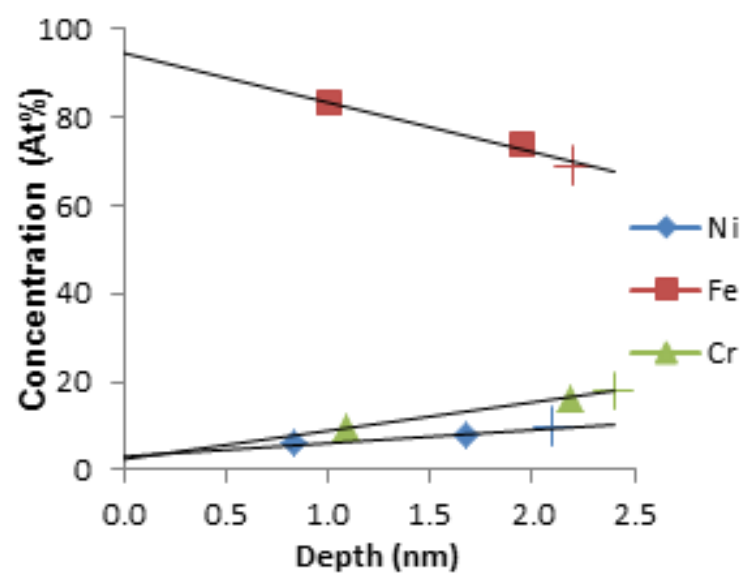

Figure 4: (Color Online) Data obtained from the survey scan after air exposure: composition plotted against depth for $2 p$ and $3 p$ peaks respectively. The points of intersection with the composition of the metal phase are marked by a cross.

\section{2) High resolution spectra data}

High resolution spectra have been recorded, for the two samples, for carbon, oxygen, iron and chromium using PARXPS in a set of 16 angles (from $25^{\circ}$ to $81^{\circ}$ ). This was done in order to obtain in-depth information without resorting to conventional ion bombardment, which is known to promote the solid-state redox reaction between iron oxide and chromium 
metal. In Figure 5 - 8 curve fittings of the integrated spectra $\left(\theta=25^{\circ}-81^{\circ}\right)$ for the peaks of the air and water exposed samples are shown. The fit has been carried out on the collapsed data (spectra obtained by summing the spectra at different angles) and then extended to the set of angle resolved data. For both samples the same chemical states are observed: the iron peak shows a pure metal component, Fe(III) and the associated satellites, indicating the presence of $\mathrm{Fe}_{2} \mathrm{O}_{3}$ (the assignment is in agreement with data reported in literature ${ }^{24}$ ); the chromium peak, in the same way, shows a pure metal component, $\mathrm{Cr}$ (III) and associated satellites, because of the presence of $\mathrm{Cr}_{2} \mathrm{O}_{3}$ (in agreement with data reported in reference ${ }^{25}$ ); oxide, hydroxide and water are observed in the $\mathrm{O} 1$ s peak; and finally $\mathrm{C}-\mathrm{C}, \mathrm{C}-\mathrm{C}=\mathrm{O}, \mathrm{C}-\mathrm{O}$ and $\mathrm{C}=\mathrm{O}$ in the $\mathrm{C}$ 1s peak. In Figure 9, the elemental concentration as a function of the take-off angle, for both samples, is reported. Similar trends are visible for both samples: the carbon concentration increases going towards glancing angles. This is more pronounced for the water exposed sample. $\mathrm{OH}^{-}$and $\mathrm{H}_{2} \mathrm{O}$ follow a similar trend demonstrating to be present on the surface. The $\mathrm{O}_{2}^{-}$peak and the metallic components show the opposite trend because relegated under the previous layers. 

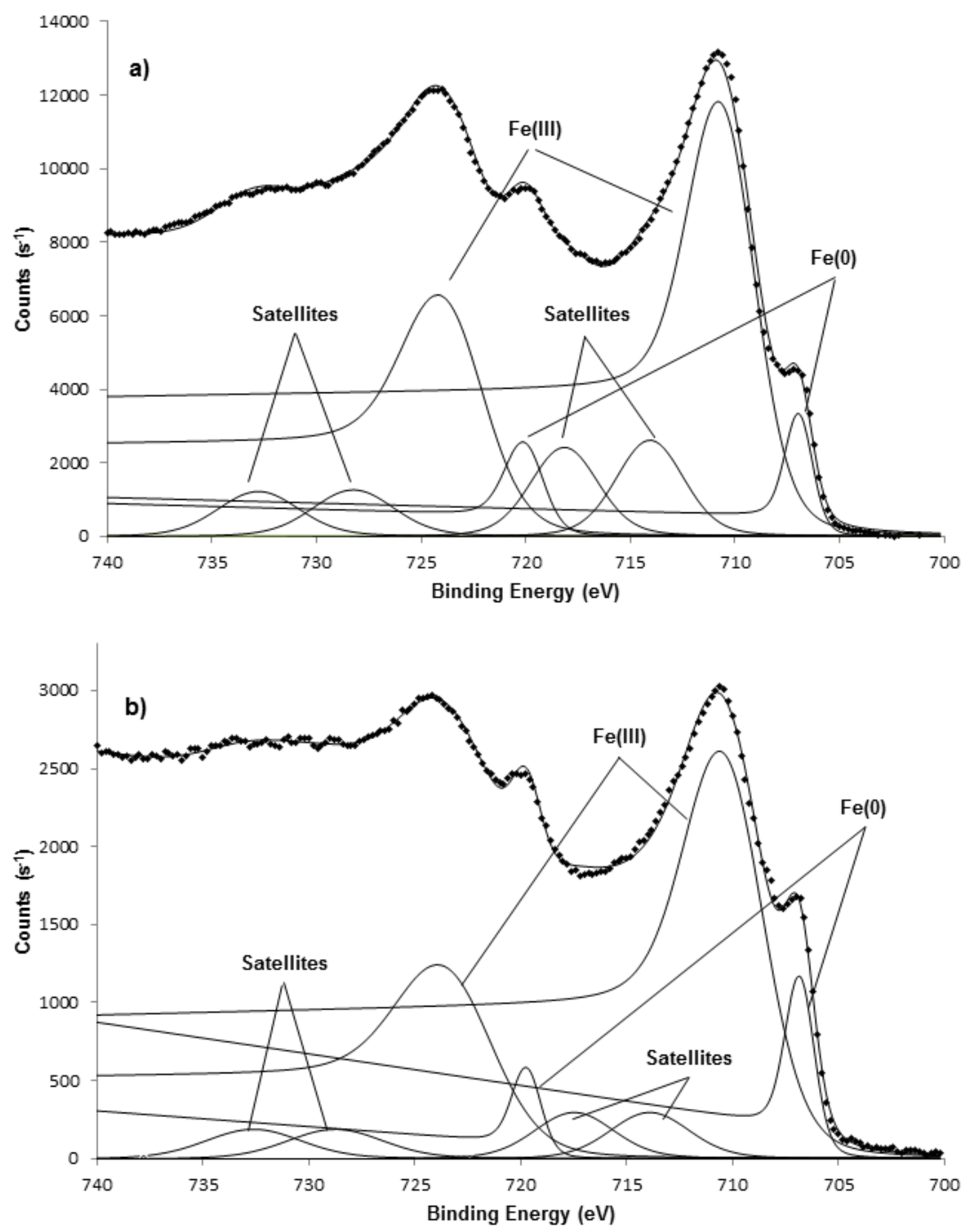

Figure 5: Fe2p high resolution fitted peaks for a) air exposed steel and b) water exposed steel. 

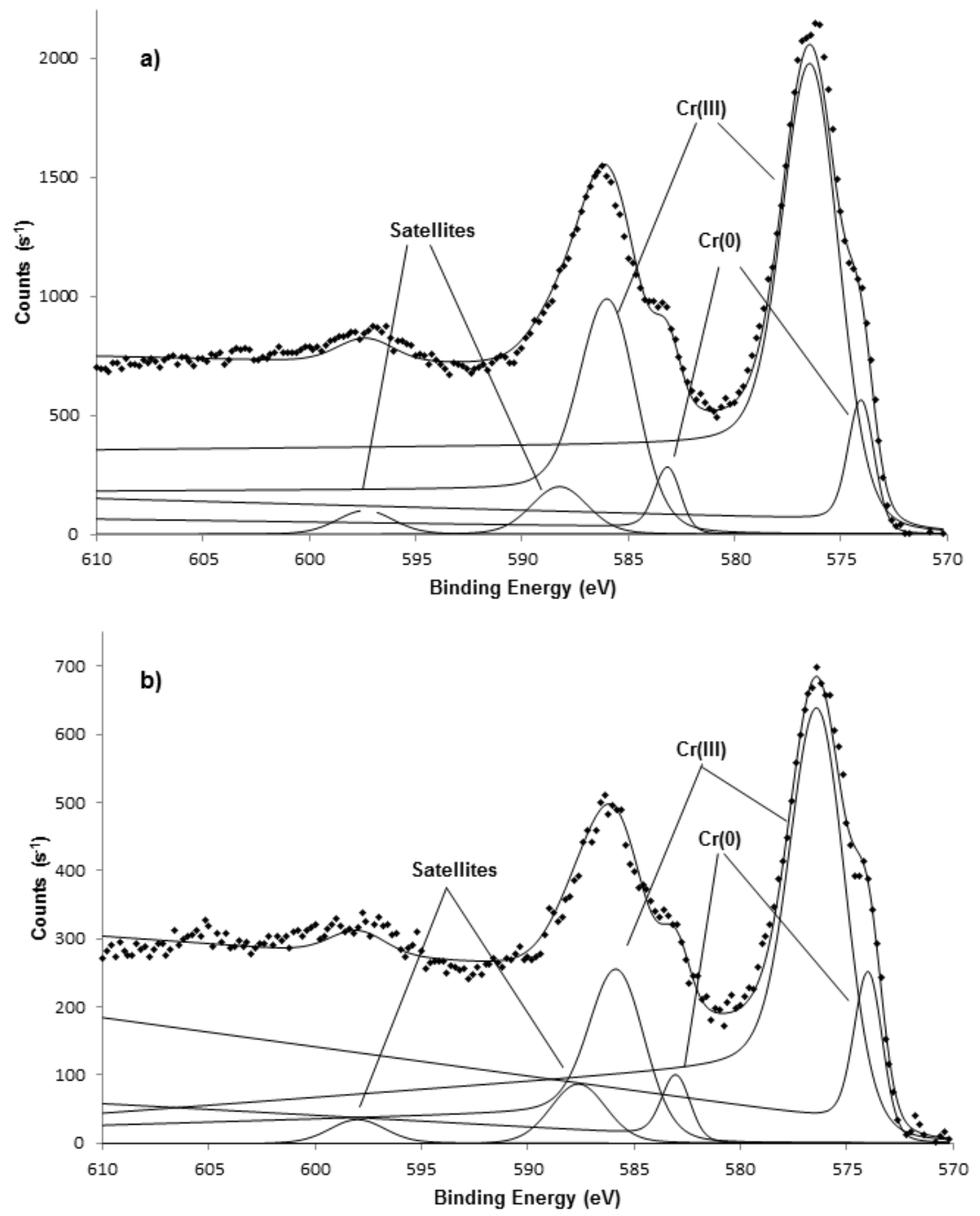

Figure 6: Cr2p high resolution fitted peaks for a) air exposed steel and b) water exposed steel. 

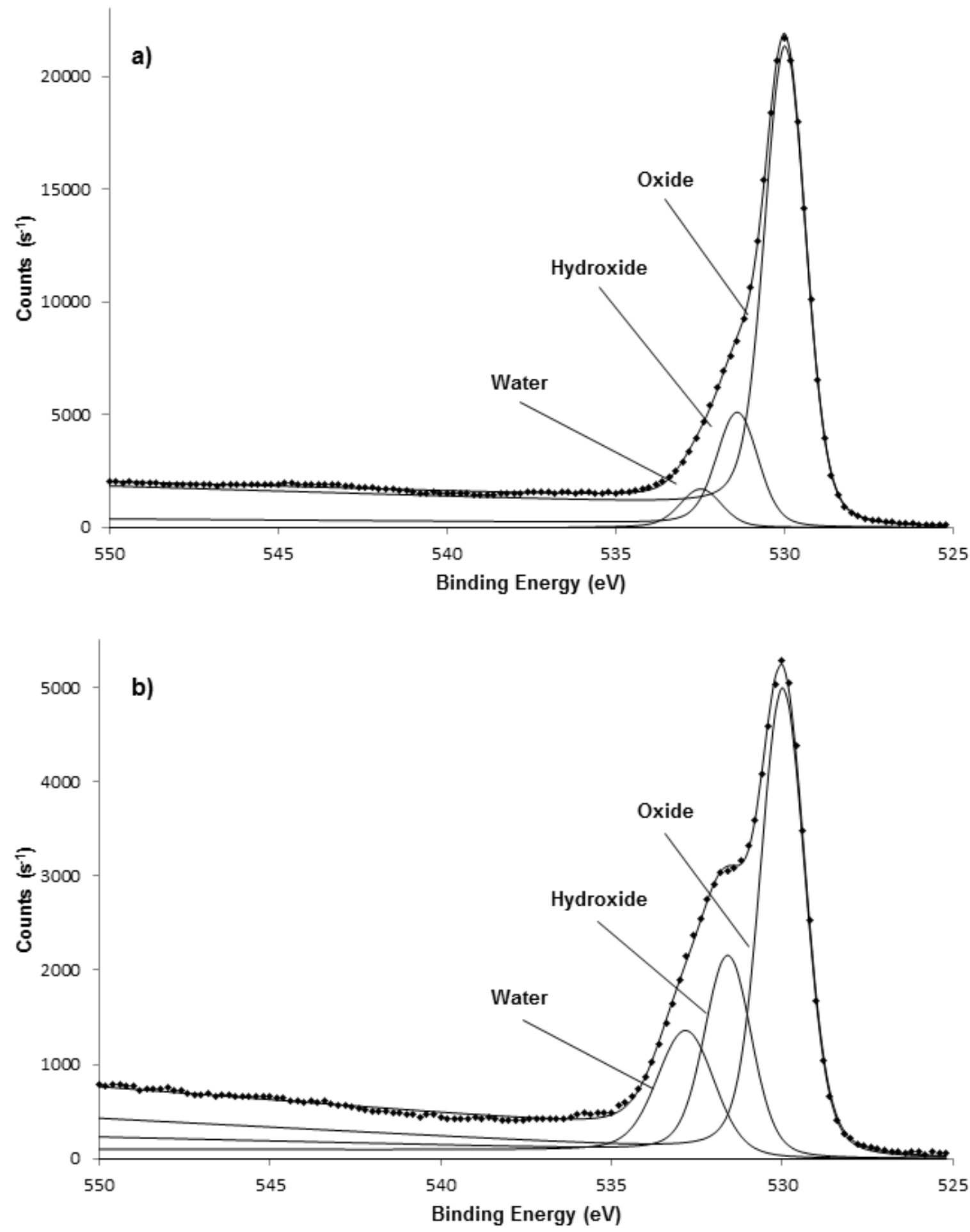

Figure 7: O1s high resolution fitted peaks for a) air exposed steel and b) water exposed steel. 

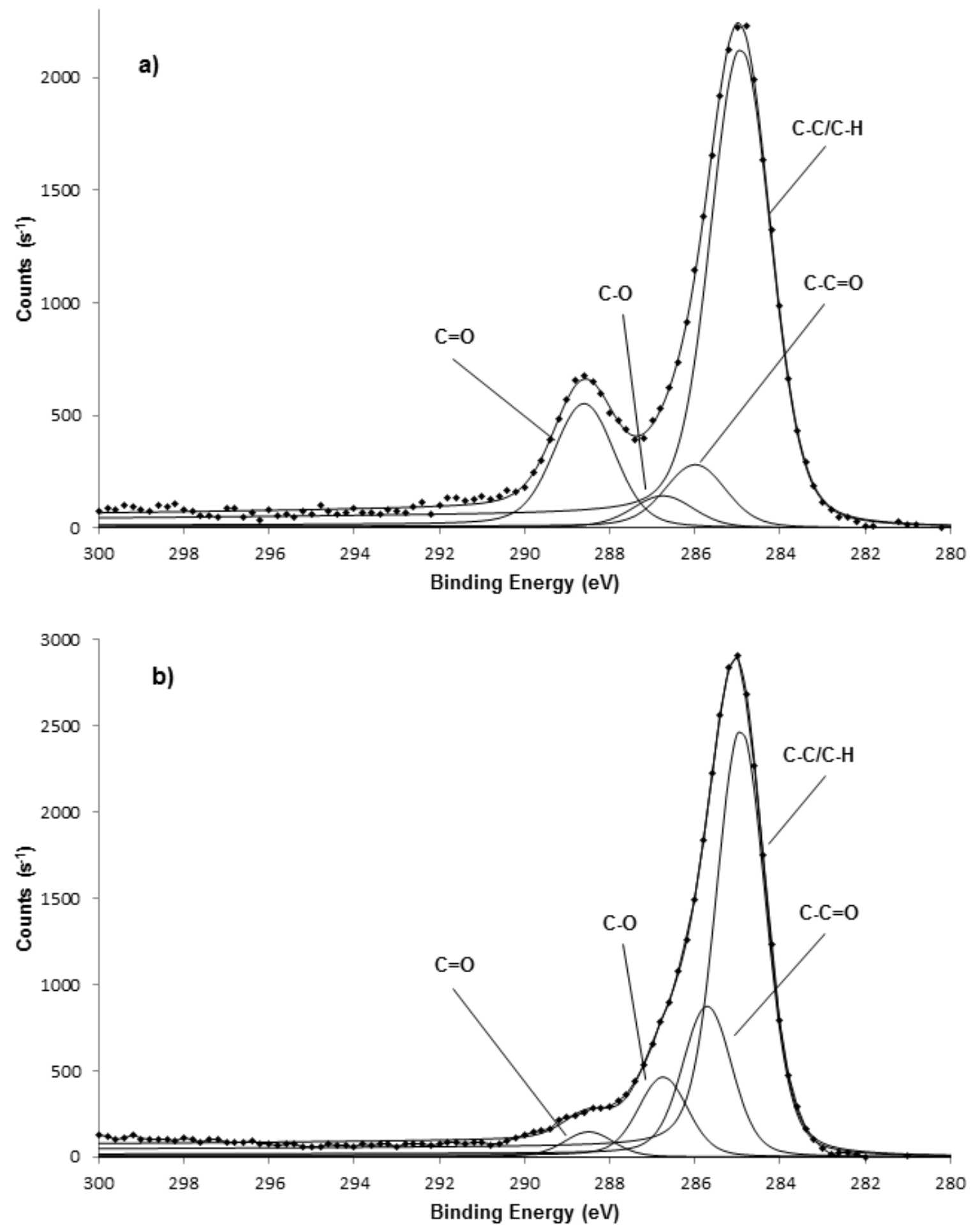

Figure 8: C1s high resolution fitted peaks for a) air exposed steel and b) water exposed steel. 

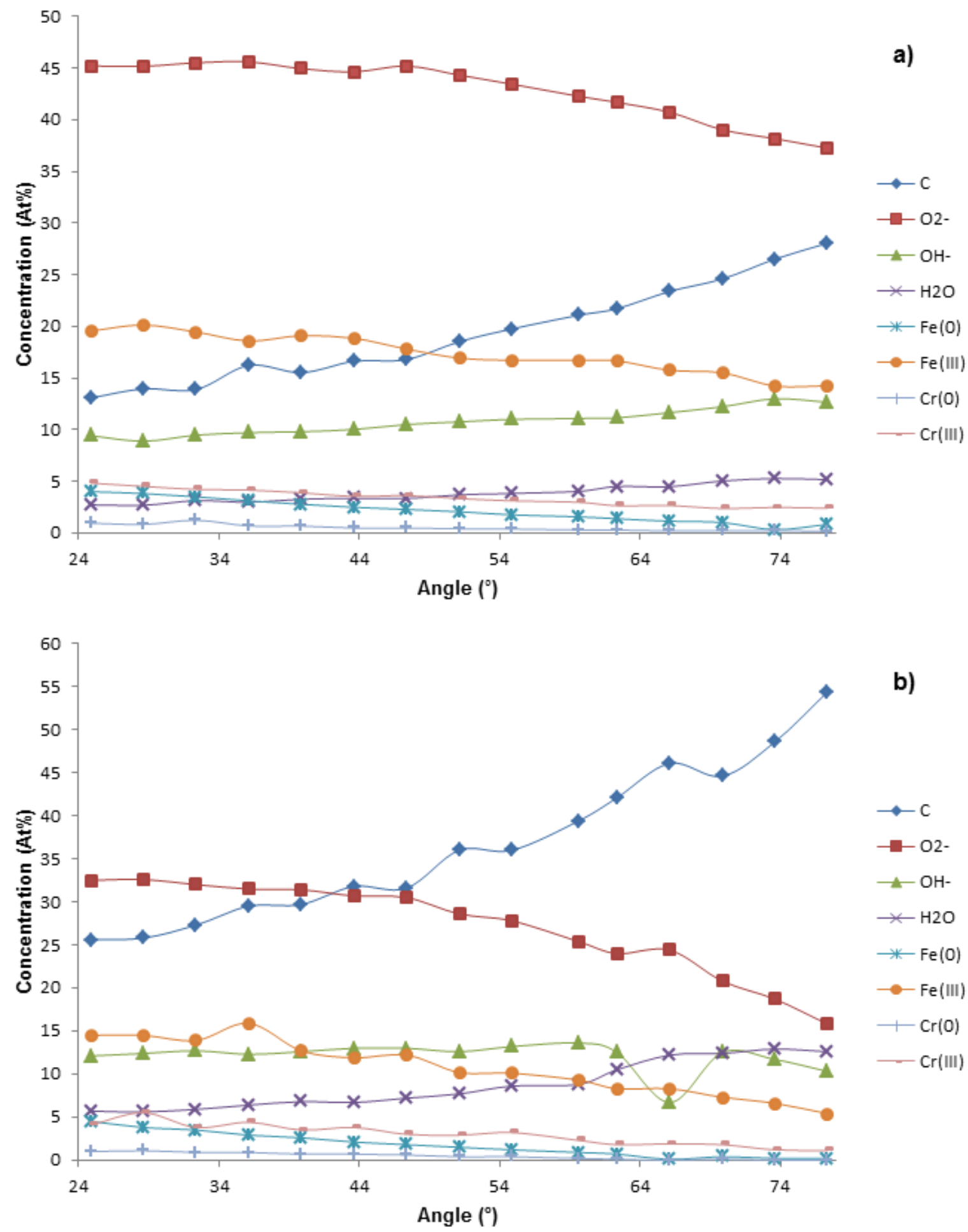

Figure 9: (Color Online) XPS angular profile of a) air exposed steel and b) water exposed steel.

It is important to confirm that the carbon 1s signal is just a consequence of adventitious hydrocarbon contamination deposited during the air and water exposure which followed the preparation of the samples by ion etching. This is a common observation in surface analysis 
and it is a result of the thermodynamic driving force that exists for the material to reduce the surface free energy, this being readily accomplished by the adsorption of a vanishingly thin layer of air-borne hydrocarbon. The alternative is the reaction of pre-existing hydrocarbon during the ion etching process to produce a carbide-like surface phase, involving cations of the passive film. Identification of the carbon $1 \mathrm{~s}$ as arising from a surface film enables its thickness to be estimated and the quantification to be adjusted for its influence. In the present case this allows the $2 p$ and $3 p$ peak intensities to be used to estimate the oxide thickness. Following the rules given by Castle ${ }^{16,17}$ it is possible to confirm that the carbon peaks present in the spectra are a result of contamination. The Shirley scatter parameter $\mathrm{k}^{26}$ is 1.0 for the air exposed sample and 1.1 for the water exposed sample, thus both higher than 0.1 as required (this is because the $\mathrm{C} 1 \mathrm{~s}$ peak, from contamination, is more asymmetric in shape than other organic compounds). Also, the fact that the background slope is slightly decreasing confirms that the peak is due the contamination as it means that the element is in the outermost layer. Furthermore, a final confirmation is given by comparing the elements angle ratio $\mathrm{Q}$ (the concentration of the element at a glancing angle of $51^{\circ}$ divided by the concentration at a bulk angle of $25^{\circ}$ ) from the ARXPS measurements. The take-off angle of $51^{\circ}$ was chosen as it represents the higher angular resolved data of the set closer to the value of $53^{\circ}$ of the integrated data. For the air exposed sample the ratios are as follows: $\mathrm{Q}_{\mathrm{C}}=1.6, \mathrm{Q}_{\mathrm{O}}=1.0, \mathrm{Q}_{\mathrm{Fe}}=$ 0.9 and $\mathrm{Q}_{\mathrm{Cr}}=0.6$, whilst for the water exposed sample the ratios are: $\mathrm{Q}_{\mathrm{C}}=1.3, \mathrm{Q}_{\mathrm{O}}=0.9, \mathrm{Q}_{\mathrm{Fe}}$ $=0.7$ and $\mathrm{Q}_{\mathrm{Cr}}=0.6$. The carbon angle ratio is higher than all the others elements angle ratios, for both the samples, meaning that the carbon is only a surface layer.

The thickness of this contamination layer for both air and water exposed samples has been evaluated again using the high resolution angle resolved data by means of Equation 3. This 
was necessary since more accurate results are obtainable when the take-off angle range is smaller.

The thickness of the contamination layer, determined using this algorithm and calculated as the mean of the values obtained at each angle, was $0.4 \mathrm{~nm}$ for the air exposed sample and 0.9 $\mathrm{nm}$ for the water exposed one. The water sample value is slightly lower than the value obtained by means of the survey, which can however still be used as a first approximation. The same correction procedure applied in the survey section was applied to the angle resolved set of data. In Table IV, the original and the corrected concentrations, at an intermediate angle of $51^{\circ}$, are shown.

Table IV: Original concentrations and corrected concentrations of the elements in air and water exposed steel obtained by XPS at an angle of 51 degrees.

\begin{tabular}{l|llllllll}
\hline \hline Air & $\mathbf{F e}(\mathbf{0})$ & $\mathbf{F e}(\mathbf{I I I})$ & $\mathbf{C r}(\mathbf{0})$ & $\mathbf{C r}($ III) & $\mathbf{O}_{2}^{-}$ & $\mathbf{O H}^{-}$ & $\mathbf{H}_{2} \mathrm{O}$ & $\mathbf{C}$ \\
\hline Original & 2.1 & 16.9 & 0.4 & 3.3 & 44.3 & 10.8 & 1.7 & 18.5 \\
Corrected & 2.5 & 21.0 & 0.5 & 4.0 & 54.2 & 13.2 & 4.5 & \\
\hline Water & $\mathbf{F e}(\mathbf{0})$ & $\mathbf{F e}(\mathbf{I I I})$ & $\mathbf{C r}(\mathbf{0})$ & $\mathbf{C r}(\mathbf{I I I})$ & $\mathbf{O}_{2}^{-}$ & $\mathbf{O H}^{-}$ & $\mathbf{H}_{2} \mathbf{O}$ & $\mathbf{C}$ \\
\hline Original & 1.5 & 10.2 & 0.4 & 2.9 & 28.6 & 12.6 & 7.7 & 36.1 \\
Corrected & 2.4 & 16.4 & 0.6 & 4.3 & 44.6 & 19.6 & 12.0 & \\
\hline \hline
\end{tabular}

The background of an XPS peak, in the region of 50-100 eV lower kinetic energy (and thus higher binding energy) is related to the extrinsic energy losses associated with the transport of photoelectrons through the solid; the deeper the element is in the solid, the more its electrons will be inelastically scattered, showing a higher binding energy and so giving a rising background on the left side of the peak ${ }^{27}$. This phenomenon is particularly strong in the case of the $3 \mathrm{~d}$ transition metals. $\mathrm{Fe} 2 \mathrm{p}$ and $\mathrm{Cr} 2 \mathrm{p}$ peaks have a steeply rising background and for this reason it was necessary to fit the spectra with a Shirley function multiplied by a polynomial function expressed in Eq. 1. The Kappa parameters employed were found in the 
literature $^{12}$. Concerning the $\mathrm{B}_{1}$ value, which is the slope parameter of the peak tail, was fixed to a certain value (for the same angle and the same sample) for the metallic component and left free to be optimized by the software for the cationic component. It is useful to notice how the tail slope of the metal component is expected to be negative whilst the one of the oxide component is expected to be positive or flat as the metallic iron will clearly be beneath the thin air-formed passive film or the film modified upon water exposure. Therefore, for the metallic components a positive value of $\mathrm{B}_{1}$ was chosen as it is expected to be underneath its oxide, and an increasing background is expected. The comparison of the $\mathrm{B}_{1}$ parameters (which are reported in Table $\mathrm{V}$ for the collapsed data set) obtained for the cationic component of iron and chromium, for both the samples, provides information about the presence of these elements in the surface and possible gradients of concentration. This information is consisted with the enrichment factors observed from the survey spectra.

Table V: B1 values for $\mathrm{Fe}$ and $\mathrm{Cr}$ collapsed peak for air and water exposed stainless steel

\begin{tabular}{l|ccc}
\hline \hline B1 & $\mathbf{F e}(\mathbf{0}) / \mathrm{Cr}(\mathbf{0})$ & $\mathbf{F e}($ III $)$ & $\mathbf{C r}(\mathbf{I I I})$ \\
\hline Air exposed & $2.79 \times 10^{-3}$ & $-2.12 \times 10^{-4}$ & $-1.36 \times 10^{-4}$ \\
Water exposed & $1.00 \times 10^{-2}$ & $-2.95 \times 10^{-4}$ & $-1.14 \times 10^{-3}$ \\
& & & \\
\hline \hline
\end{tabular}

Figure 10 shows the fitted high resolution spectra of the O1s peak for both the air and the water exposed samples at two different take-off angles. This enables the determination of where the hydroxide and water layer are localized in the surface and in which samples their quantity is higher. 

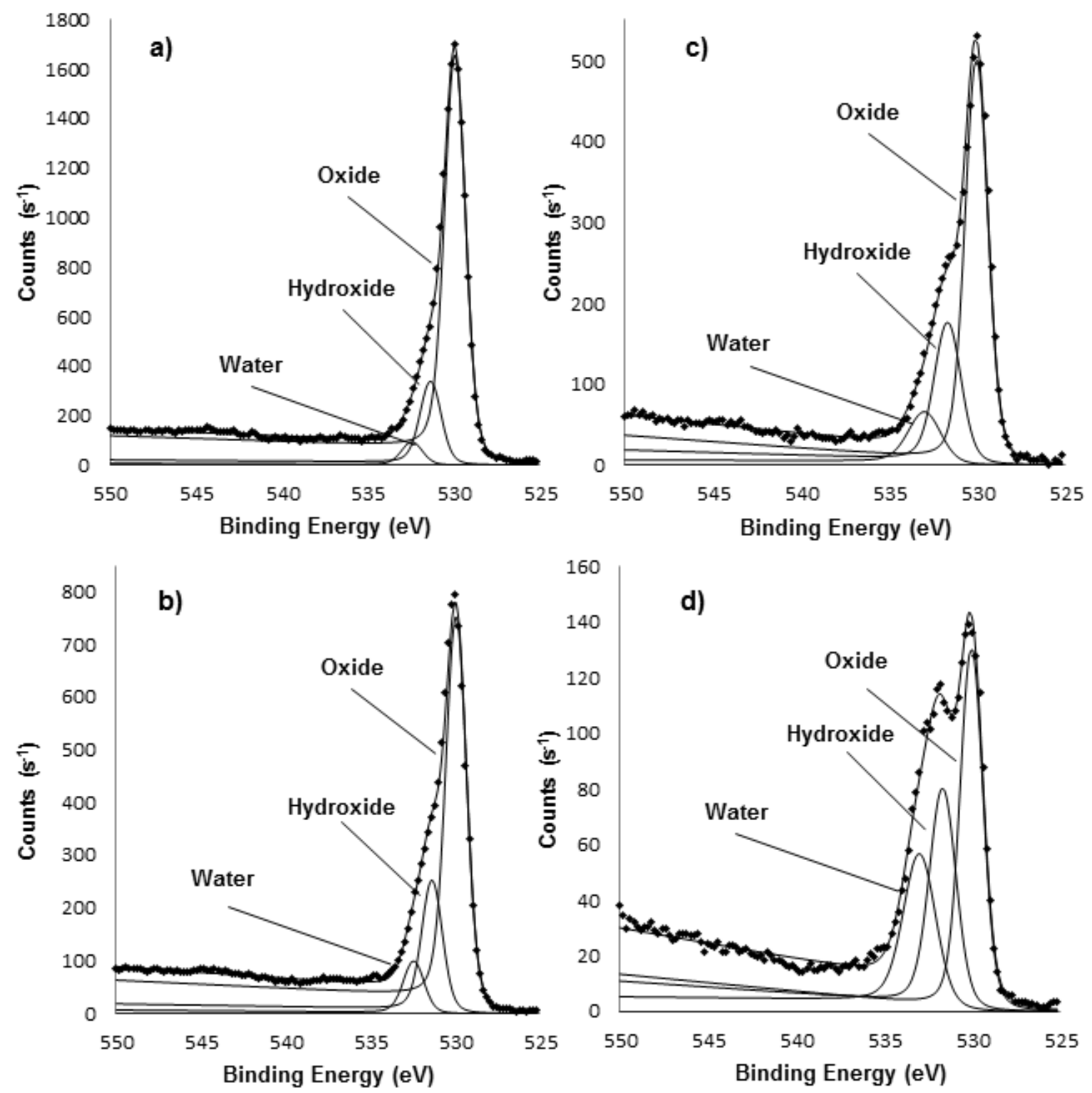

Figure 10: $01 \mathrm{~s} \mathrm{high} \mathrm{resolution} \mathrm{spectra} \mathrm{for} \mathrm{a)} \mathrm{air} \mathrm{exposed} 25^{\circ}$, b) air exposed $74^{\circ}$, c) water exposed $25^{\circ}$ and d) water exposed $74^{\circ}$, steel.

One of the standard procedures in the analysis of oxide films on pure metals is the determination of the oxide layer thickness by consideration of the metallic and cationic contributions to the high resolution XPS spectrum. This is performed by means of an equation derived from the Beer-Lambert equation: 


$$
d=\lambda_{\text {metal,oxide }} \cos \theta \ln \left(1+R / R_{R^{\infty}}\right)
$$

where $\mathrm{R}$ is the ratio of the calculated intensity of the metal component and the oxide one, whilst $\mathrm{R}^{\infty}$ is the analogous ratio coming from two infinitely thick layers. In a series of angle resolved data, by plotting $\ln \left[1+\mathrm{R} / \mathrm{R}^{\infty}\right]$ as function of $1 / \cos \theta$, a straight line should be obtained. The slope of this line will be given by $\mathrm{d} / \lambda$, so the thickness of the oxide can be obtained. Unfortunately, this procedure is not so straightforward in the case of alloys because of the presence of two cations which do not have the same concentration and are not uniformly distributed over the oxide layer. If this equation was applied separately to both iron and chromium peaks, two different thicknesses for the oxide layer would be found. This happens because the two metals do not have the same concentration ratio they have in the bulk of the alloy. That means that their $\mathrm{R}^{\infty}$ cannot be considered the same for both and depends on the enrichment or depletion of the element in the oxide overlayer. A correction can be obtained by substituting $\mathrm{R}^{\infty}$ in Eq. 7 with $\mathrm{F}_{\text {met }}$ (the enrichment factor calculated previously for the two metals in the two samples for the $2 p$ peaks). The results obtained, shown in Table VI for the two metals are closer. It is necessary to emphasize that this is still an approximation, as the gradient of the metals concentration in the metal oxide, has not been taken into account.

Table VI: Corrected oxide thickess considering Fe and $\mathrm{Cr}$ peaks for the air and the water exposed samples compared the thickness obtained by $2 \mathrm{p}$ and $3 \mathrm{p}$ peaks from the survey scan.

\begin{tabular}{l|lll}
\hline \hline Oxide & Air & Water & Air From survey \\
\hline Fe & $1.8 \mathrm{~nm}$ & $2.1 \mathrm{~nm}$ & $2.2 \mathrm{~nm}$ \\
$\mathbf{C r}$ & $1.9 \mathrm{~nm}$ & $1.4 \mathrm{~nm}$ & $2.4 \mathrm{~nm}$ \\
Oxide Thickness & $1.85( \pm 0.05) \mathrm{nm}$ & $1.75( \pm 0.35) \mathrm{nm}$ & $2.3( \pm 0.1) \mathrm{nm}$ \\
\hline \hline
\end{tabular}




\section{b) Tof-SIMS Data}

The ToF-SIMS positive spectra (
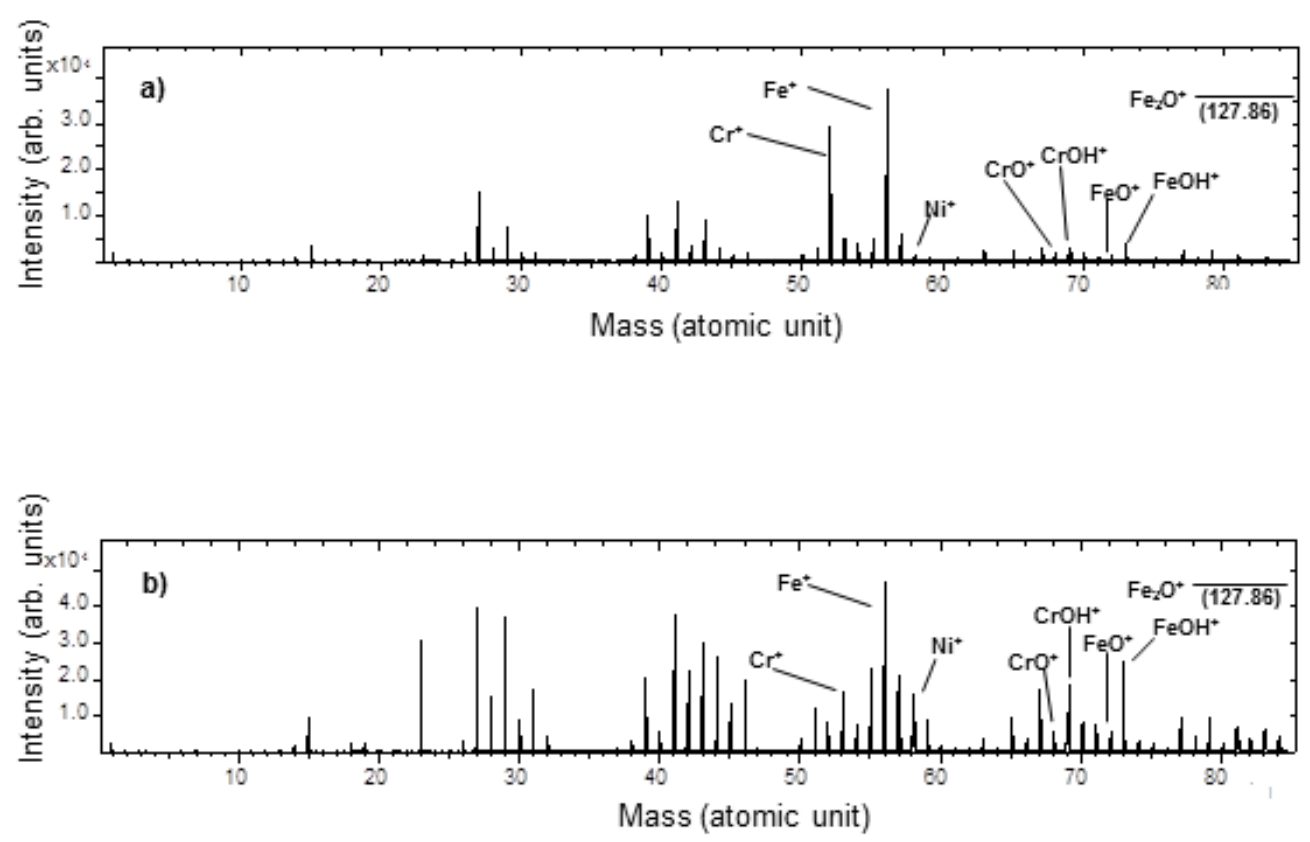

Figure 11) of the two samples show the presence of Iron, chromium and nickel on the surface, but no molybdenum, which is visible in the XPS. 

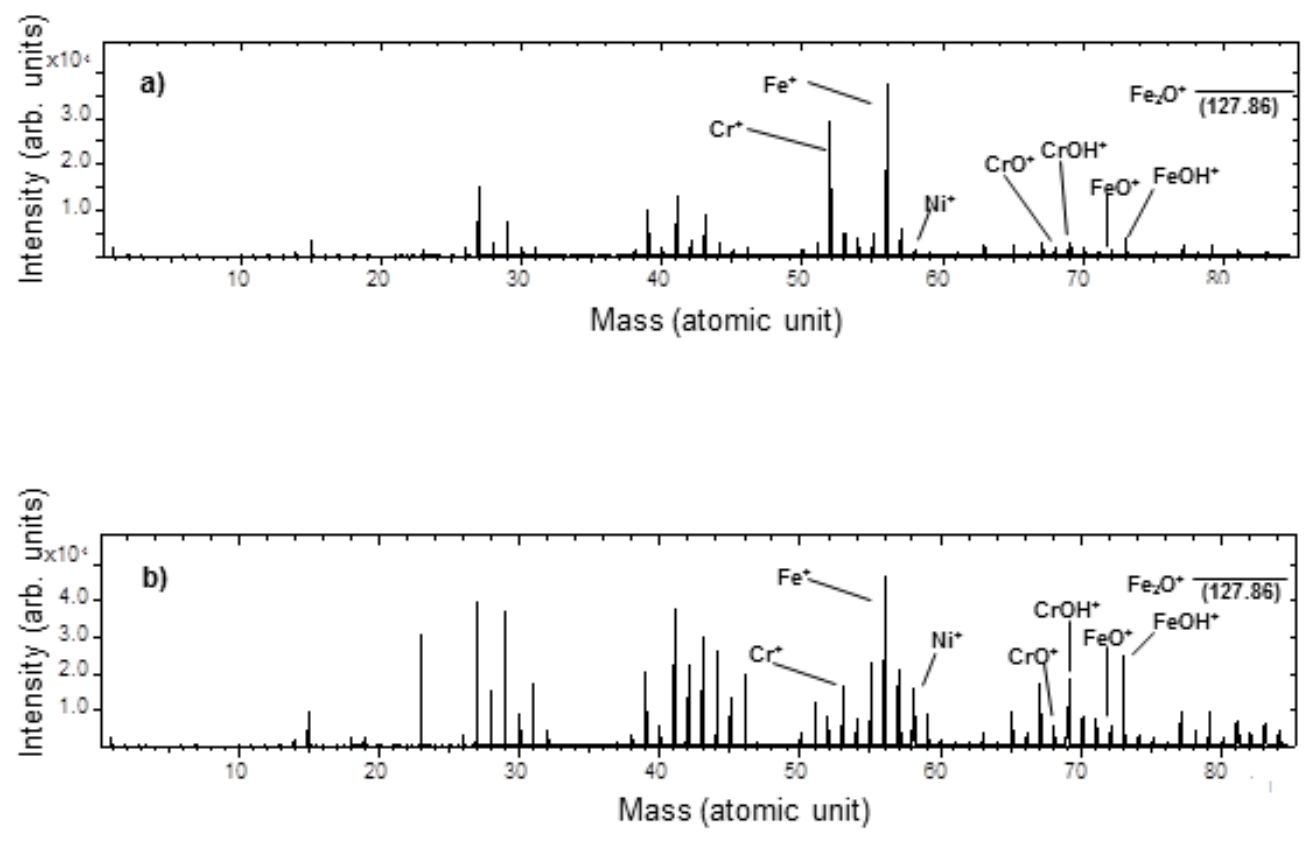

Figure 11: SIMS positive spectrum of a) air exposed steel and b) water exposed steel.

It is well known that depth profiling of extremely thin air-formed films of the type considered in this paper present significant problems in SIMS, particularly dynamic SIMS although the situation is somehow more straightforward in ToF-SIMS profiling. As the air formed film is extremely thin it is often removed in the very early stages of elemental ion sputter profiling and additionally a redox reaction may well occur between substrate and passive film. Cluster ions have a significantly lower sputter rate for inorganic materials and thus it is possible to profile such a thin film with improved precision. This is also true for XPS. For these reasons, a Buckminster Fullerene $\left(\mathrm{C}_{60}{ }^{+}\right)$cluster beam was chosen.

Considering the depth profile, as the $\mathrm{Cs}^{+}$ions commonly used for sputtering combine with iron and chromium over time, it is impossible to follow the profile of the metals and their oxides unambiguously with this technique. Similarly, the use of $\mathrm{Ar}^{+}$ions can bring about ion 
beam reduction and the potential reduction of the metallic cations to a lower valence state.

The results obtained show the feasibility of this method applied to thin oxide layers.

In order to obtain a depth profile from the etching time profile, the data sets collected from XPS were used. In particular, the thicknesses calculated for the oxide layers in the two samples were used to relate the depth with the etching time. The time at which the $\mathrm{CrO}^{+}$ion signal drops down was equated to the thickness of the respective oxide layer (Figure 12).
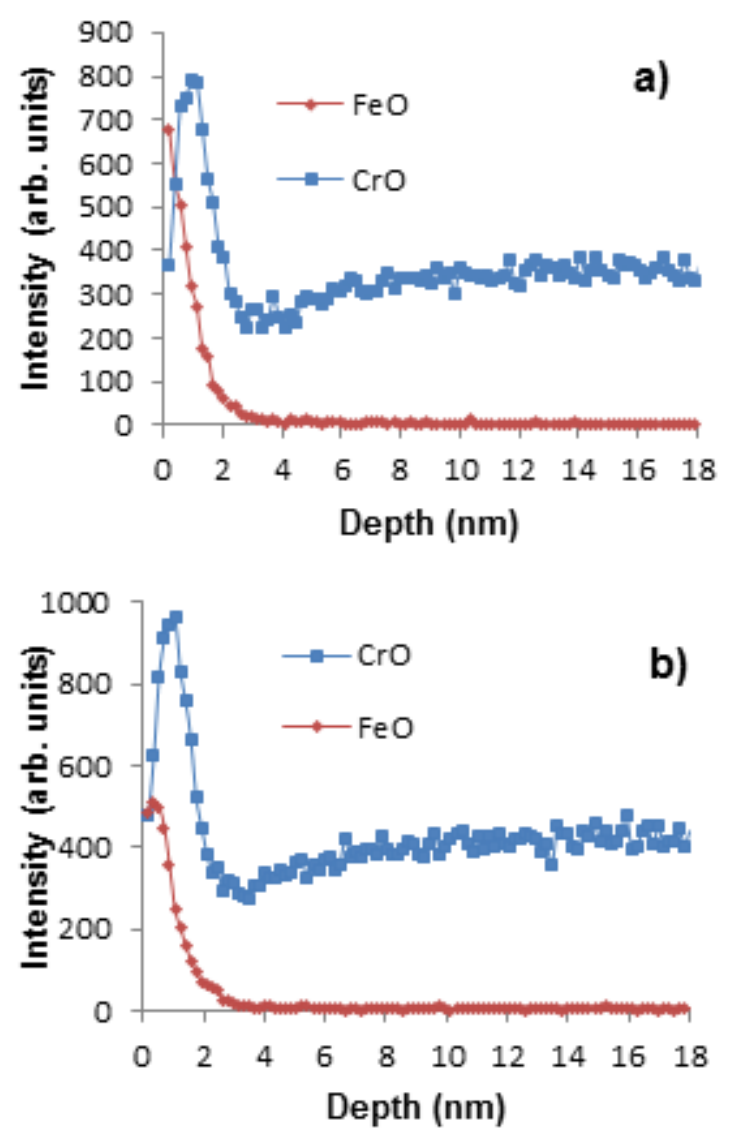

Figure 12: (Color Online) SIMS Depth profile of the ions $\mathrm{FeO}^{+}$and $\mathrm{CrO}^{+}$for a) air exposed and b) water exposed steel.

Figure 13 shows the profile of a) the ions $\mathrm{CrO}^{+}, \mathrm{CrOH}^{+}$and $\mathrm{CrOH}_{2} \mathrm{O}^{+}$and b) the one for $\mathrm{FeO}^{+}, \mathrm{FeOH}^{+}$and $\mathrm{FeOH}_{2} \mathrm{O}^{+}$for the air exposed sample. The water exposed sample profiles for these ions show the same trend. It is now possible to calculate the thickness of the different layers. 

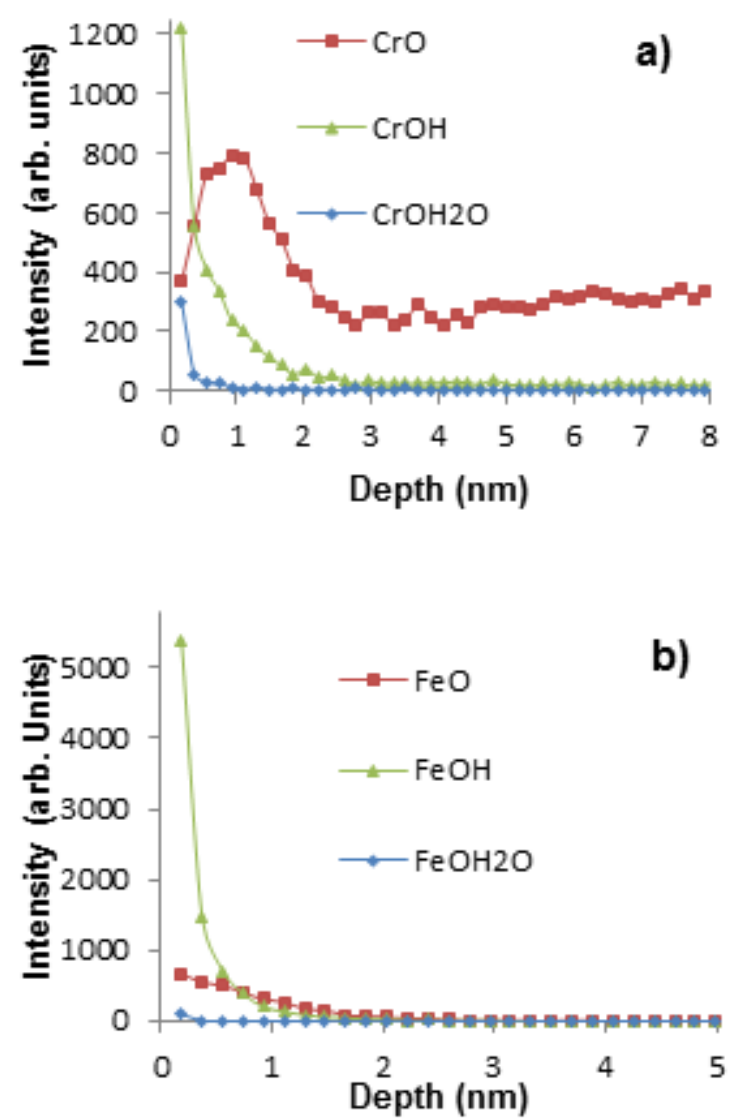

Figure 13: (Color Online) Depth profile of the ions a) $\mathrm{CrO}^{+}, \mathrm{CrOH}^{+}, \mathrm{CrOH}_{2} \mathrm{O}^{+}$and b) $\mathrm{FeO}^{+}, \mathrm{FeOH}^{+}$, $\mathrm{FeOH}^{+} \mathrm{O}^{+}$for air exposed steel.

In the profiles it is possible to notice that whilst for the fragment $\mathrm{FeO}^{+}$the peak intensity drops to zero, for the fragment $\mathrm{CrO}^{+}$some intensity is still detected after sputtering. This can be explained by the fact that, even if under ultra-high vacuum, same oxygen is still present in the SIMS analysis chamber and following the sputtering some of the revealed bare metal will oxidize. As the enthalpy of formation of $\mathrm{Cr}_{2} \mathrm{O}_{3}$ is lower (more negative) than the $\mathrm{Fe}_{2} \mathrm{O}_{3}$ one, the chromium oxide will form preferentially over the iron oxide. No additional information was obtained by the negative spectra. The $\mathrm{O}^{-}, \mathrm{OH}^{-}$fragment profiles are coherent with the one observed for metal oxide and metal hydroxide positive ions.

This shows how the combination of XPS and SIMS is a very powerful method for the investigation of thin oxide layers on metals. 


\section{DISCUSSION}

The XPS survey spectrum of the air exposed sample shows, as illustrated in Figure 1, the presence at the surface of carbon contamination and implanted argon (due to presputtering). There are peaks characteristic of the native oxide film and sub-surface metal: $\mathrm{O} 1 \mathrm{~s}, \mathrm{Cr} 2 \mathrm{p}, \mathrm{Fe} 2 \mathrm{p}$, weak NiLMM (the main Ni2p spectrum is subsumed within the FeLMM Auger transition) features and the Mo3d doublet. As can be seen in Figure 2 the same peaks are visible for the water exposed sample. Also the SIMS positive spectra illustrated in
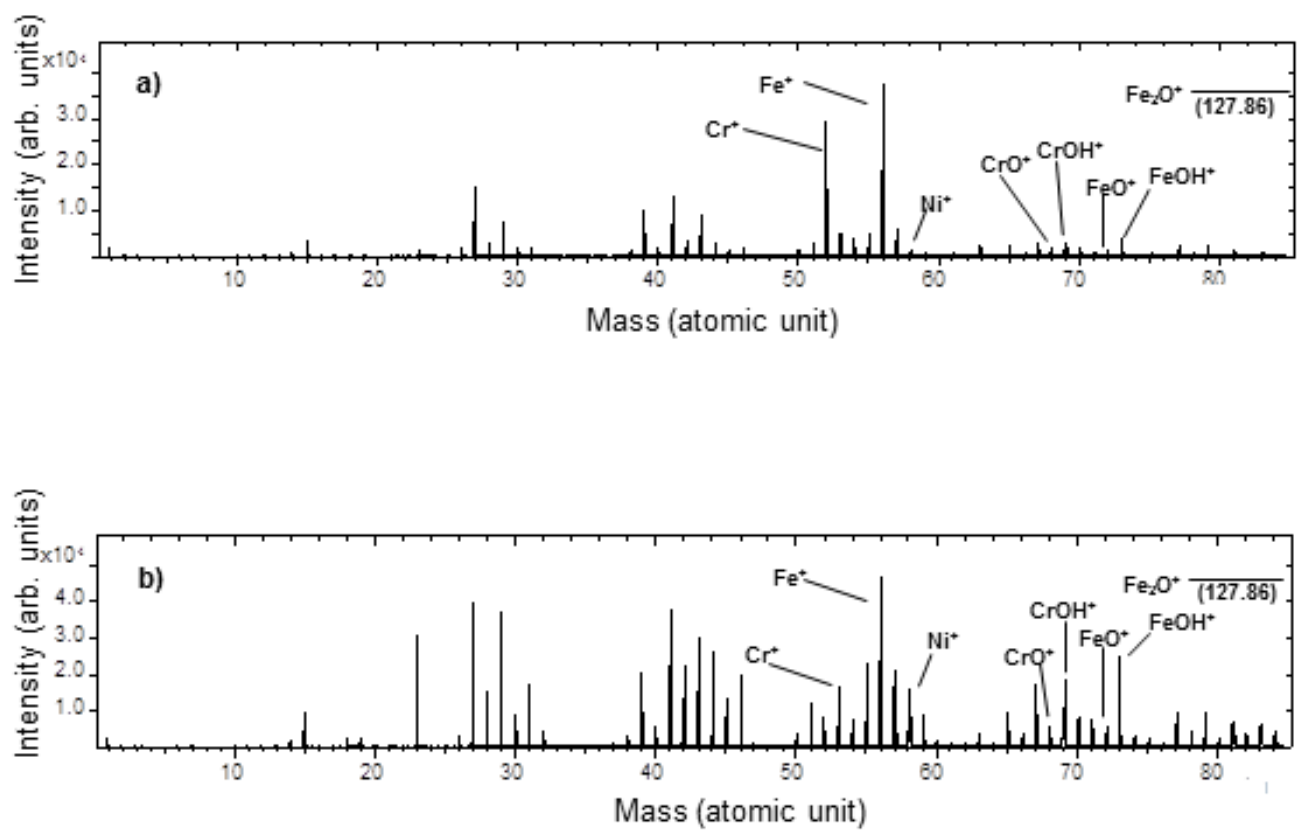

Figure 11 shows the presence of iron, chromium and nickel but not molybdenum. As the SIMS analysis is more surface sensitive than XPS, this seems to suggest the molybdenum is present at the interface between the oxide and the substrate. It is possible to underline that the high resolution spectra of molybdenum by XPS shows the presence of different oxidation states (Figure 14). 


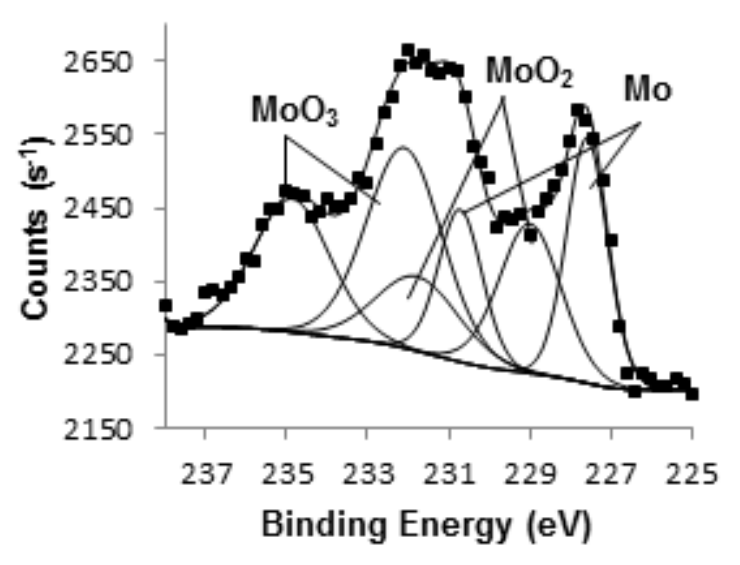

Figure 14: Mo3d high resolution spectrum for air exposed steel.

By comparing the nickel enrichment factors for $2 p$ and $3 p$ peaks obtained by means of the high resolution spectra (Table III), it is conceivable that this element is also enriched at the interface between the bulk alloy and the oxide.

By curve fitting the peaks (Figure 5 - 7), it is possible to identify a pure metal component and a $\mathrm{Me}(\mathrm{III})$ one for iron and chromium, indicating the presence of an oxide overlayer made of $\mathrm{Fe}_{2} \mathrm{O}_{3}$ and $\mathrm{Cr}_{2} \mathrm{O}_{3}$. For the oxygen, there are three components visible: oxide, hydroxide and water.

Observing SIMS data in the profile in Figure 12, it is possible to notice that the $\mathrm{FeO}^{+}$ ion is enriched in the first nanometer of the surface and the $\mathrm{CrO}^{+}$just underneath. This matches with the observation made with XPS by means of the enrichment factors. By comparing the enrichment factors for the $2 \mathrm{p}$ and the $3 \mathrm{p}$ peaks a gradient of concentration which follows the given trend was evident (Table III).

Some important differences between the two samples are apparent. The quantitative XPS data is presented in Table IV; in the water exposed sample the carbon contamination is higher. The contamination layer, which is naturally adsorbed onto the high free-energy steel oxide surface, is significantly thicker on the water exposed sample (as shown in Table III). This is probably accumulated when the metal coupon is taken out of the water and comes into 
contact with the meniscus. This difference in the contamination layer explains the larger value of the $\mathrm{B}_{1} \mathrm{~s}$ (Table $\mathrm{V}$ ) of the metallic component in the water exposed samples: the photoelectrons have to cross more material.

Inspection of the energy loss backgrounds of iron and chromium (from Figure 5 and Figure 6) suggests that for the air exposed sample the iron oxide is present above the chromium oxide layer as stated before. In the second sample, the iron peak shows a negative slope of the background meaning that the signal comes from beneath the surface. It can be assumed, in this case, that most of the background emanates from the metallic iron underneath the oxide. This visual observation can be confirmed by comparing the B1 values listed in Table V. The parameter, which indicates the slope of the background, and is therefore proportional to the length of the travel of the photoelectron through the overlayers, is lower for the $\mathrm{Fe}$ (III) component compared to the $\mathrm{Cr}(\mathrm{III})$ one (confirming that the $\mathrm{Fe}_{2} \mathrm{O}_{3}$ is more concentrated on the top surface), however, for the water exposed sample, the opposite is true, as most of the background is due to the metallic component. The Fe intensity is also lower in the water exposed sample. All this could be explained by a preferential dissolution of iron oxide in water ${ }^{28}$. On water exposure the outermost Fe(III) component of the passive film is removed and now underlies the $\mathrm{Cr}$ (III) component. This observation is further confirmed by inspection of the $\mathrm{Cr} 2 \mathrm{p}$ spectra of Figure 6. The spectra are more similar to each other if compared to the differences seen in the Fe peaks. The $\mathrm{Cr}$ (III) containing component of the passive film remains in place whilst the Fe(III) is dissolved. The similarity of background structure for the iron and chromium components of the water exposed film confirms the co-location of $\mathrm{Fe}(\mathrm{III})$ and $\mathrm{Cr}(\mathrm{III})$ in the oxide layer. This mechanism can also be used to explain the difference in the enrichment factors for iron and chromium in the two samples. The factors appear to diminish for iron after water exposure and increase for chromium. The SIMS data appear to match with the XPS data. Comparing the profiles of the 
two samples it is also possible to notice that the intensity ratio iron/chromium is bigger for the air-formed film. Although there is iron dissolution in the case of water exposure, the thickness calculated for the two oxide layers, seems to be the same (Table VI).

The high resolution O1s spectra of Figure 10 show that there are water and hydroxide layers present at the surface of both the samples; that is explained by the fact that the intensities of the $-\mathrm{OH}$ and $\mathrm{H}_{2} \mathrm{O}$ peaks are higher at the glancing angle than at bulk angle for both the samples. The spectra also show that these components are more concentrated in the water exposed sample; for both angles the intensities of - $\mathrm{OH}$ and $\mathrm{H}_{2} \mathrm{O}$ components in the water-exposed sample are significantly higher than in the air-exposed sample. This information would explain why the thickness of the two oxides is the same even after iron oxide depletion; the thicker hydroxide and water adsorbed layer in the water exposed samples makes up the lost iron oxide, compensating for the overall thickness.

Figure 13 illustrates the profile in a) for the ions $\mathrm{CrO}^{+}, \mathrm{CrOH}^{+}$and $\mathrm{CrOH}_{2} \mathrm{O}^{+}$and in b) for the ions $\mathrm{FeO}^{+}, \mathrm{FeOH}^{+}$and $\mathrm{FeOH}_{2} \mathrm{O}^{+}$for the air exposed sample. For both chromium and iron based ions, the depth profile shows a water absorbed layer at the very surface of the sample together with a thicker hydroxide layer which is placed above the oxide layer. The water adsorbed layer shows a thickness of about $0.4 \mathrm{~nm}$ and the hydroxide about $1 \mathrm{~nm}$. The hydroxide is a mix of iron and chromium hydroxide. The same trends were observed in the water exposed sample.

\section{SUMMARY AND CONCLUSIONS}

A comparative study of the air formed and water modified oxide layer, present on the surface of 316L stainless steel, has been performed with different aims;

- to build a better understanding of the nature of the native oxide film which is usually modified for several applications or studied under different environmental conditions, 
- to give information about how water (often used to wash metallic plants components or to understand corrosion behavior) can transform the passive layer,

- to provide a detailed approach showing how thin passive films can be analysed, to a high degree of confidence, by XPS,supported by ToF-SIMS sputter profile data.

A quantitative measure, by mean of XPS and ToF-SIMS, of the changes in the native oxide film, has been obtained. The following conclusions have been drawn:

1) For both the air and water exposed $316 \mathrm{~L}$ stainless steel samples there is a contamination and a water adsorbed layer followed by an hydroxide layer before the oxide. The water and hydroxide layer are more concentrated in the water exposed sample. It is suggested that the molybdenum is situated between the oxide and the substrate. In the water exposed sample, preferential dissolution of $\mathrm{Fe}_{2} \mathrm{O}_{3}$ is observed. The thickness of the mixed oxide layer is estimated to be $1.85( \pm 0.05) \mathrm{nm}$ for the air exposed steel and $1.75( \pm 0.35) \mathrm{nm}$ for the water exposed steel.

2) Useful information can be obtained by the survey spectra, where peak background and differences between $2 p$ and $3 p$ peaks can be taken into account.

3) For good peak fitting of the $2 p$ XPS spectra of iron and chromium, the $2 p$ doublet peaks should be fitted together; the energy loss tail of each individual component should be taken into account as well as the satellite structure.

4) SIMS depth profile by using clusters as sputtering source is shown to be an optimal method to obtain in depth information on the thin passivation layer of stainless steel. The example in this paper uses $\mathrm{C}_{60}{ }^{+}$cluster ions but the same conclusion would be expected using massive ion clusters which are now widely used in sputter profiling by both XPS and ToF-SIMS.

5) The combination of XPS and SIMS is a powerful tool in the field of corrosion science for the analysis of ultra-thin films on metallic alloys. 


\section{References}

${ }^{1}$ P. Stefanov, D. Stoychev, M. Stoycheva, A. R. Gonzales-Elipe and Ts. Marinova, Surf. Interface Anal. 28, 106 (1999).

${ }^{2}$ P. Stefanov, D. Stoychev, M. Stoycheva and Ts. Marinova, Mater. Chem. Phys. 65, 215 (2000).

${ }^{3}$ A. Santamaria F. Di Franco, F. Di Quarto, M. Pisarek, S. Zanna and P. Marcus, J. Solid State Electrochem., DOI 10.1007/s10008-015-2849-0

${ }^{4}$ S. Trigwell and G. Selvaduray, J. Mater. Process. Tech., 166, 30 (2005).

${ }^{5}$ K. Rokosz, T. Hryniewicz and R. Rokicki, Tehnički vjesnik, 21, 799 (2014).

${ }^{6}$ T. Hanawa, S. Hiromoto, A. Yamamoto, D. Kuroda and K. Asami, Mater. Trans. 43, 3088 (2002).

${ }^{7}$ J. Gähde, J. F. Friedrich, R. Gehrke, I. Loeschecke and J. Sachse, J. Adhesion Sci. Technol, 6, 569 (1992).

${ }^{8}$ J. E. Castle, J. Adhes., 84, 368 (2008).

${ }^{9}$ C. -O. A. Olsso and D. Landolt, Electrochim. Acta, 48, 1093 (2003). 
${ }^{10}$ W. Fredriksson, S. Malmgren, T. Gustafsson, M. Gorgoi and K. Edström, Appl. Surf. Sci., 258, 5790 (2012).

${ }^{11}$ A. Proctor, GOOGLY manuals supplied at the University of Surrey.

12 J.E. Castle, H. Chapman-Kpodo, A. Proctor and A.M. Salvi., J. Electron. Spectrosc. Relat. Phenom., 106, 65 (2000).

${ }^{13}$ A.M. Salvi and J.E. Castle, J. Electron. Spectrosc. Relat. Phenom., 94, 73 (1998).

${ }^{14}$ J.E. Castle and A.M. Salvi, J. Electron. Spectrosc. Relat. Phenom., 114, 1103 (2001).

${ }^{15}$ C.J. Powell and A. Jablonski, NIST Electron Effective-Attenuation-Length Database, (NIST Standard Reference Database 82, http://nist.gov/srd/surface.htm.

${ }^{16}$ J.E. Castle., J. Vac. Sci. Technol., A, 25, 27 (2007).

${ }^{17}$ J.E Castle and M.A. Baker, J. Electron. Spectrosc. Relat. Phenom., 105, 245 (1999).

${ }^{18}$ G.C. Smith, J. Electron. Spectrosc. Relat. Phenom.,148, 21 (2005).

${ }^{19}$ A. S. Lea, K. R. Swanson, J. N. Haack, J. E. Castle, S. Tougaard and D. R. Bear, J. Electron. Spectrosc. Relat. Phenom., 42, 1061 (2010).

${ }^{20}$ K. Asami, K. Hashimoto and S. Shimodaira, Corros. Sci., 15, 151 (1978).

${ }^{21}$ J.E. Castle and K. Asami, Surf. Interface Anal., 36, 220 (2004). 
22 J,E, Castle and J.H. Qiu, Corros. Sci., 29, 220 (1989).

${ }^{23}$ M. P. Seah, J. H. Qiu, P. J. Cumpson and J. E. Castle, Surf. Interface Anal., 21, 336 (1994).

${ }^{24}$ J. F. Watts and J. Wolstenholme, An Introduction to Surface Analysis by XPS an AES, (Wiley, Chichester, 2008).

${ }^{25}$ A.M. Salvi, J.E. Castle, J.F. Watts and E. Desimoni, Appl. Surf. Sci., 90, 333 (1995).

${ }^{26}$ D. A. Shirley, Phys. Rev. B: Condens. Matter, 11, 453 (1972).

${ }^{27}$ S. Tougaard, Surf. Interface Anal., 5, 4709 (1988).

${ }^{28}$ J. H. Qiu and J. E. Castle, J. Electrochem. Soc., 138, 1908 (1991). 


\section{Tables}

Table I: Composition of AISI 316L stainless steel. Values are the maximum allowable unless a range is given which indicates minimum and maximum values.

\begin{tabular}{ccccccccccc}
\hline \multicolumn{10}{c}{ composition/Weight \% } \\
\hline \hline $\mathbf{C}$ & $\mathbf{C r}$ & $\mathbf{N i}$ & $\mathbf{M o}$ & $\mathbf{M n}$ & $\mathbf{S i}$ & $\mathbf{P}$ & $\mathbf{S}$ & $\mathbf{N}$ & $\mathbf{F e}$ \\
0.03 & $16.00-18.00$ & $10.00-14.00$ & $2.00-3.00$ & 2.00 & 0.75 & 0.05 & 0.03 & 0.10 & balance \\
\hline \hline
\end{tabular}

Table II: Concentration derived from the survey spectra.

\begin{tabular}{c|cccccc}
\hline \hline Air & $\mathbf{C}(\mathbf{1 s}) \%$ & $\mathbf{O}(\mathbf{1 s}) \%$ & $\mathbf{F e} \%$ & $\mathbf{C r} \%$ & $\mathbf{N i} \%$ & $\mathrm{Mo}(\mathbf{3 d}) \%$ \\
\hline $\mathbf{2 p}$ & 18.5 & 49.0 & 27.0 & 3.0 & 2.0 & 0.5 \\
$\mathbf{3 p}$ & 20.5 & 54.5 & 18.5 & 4.0 & 2.0 & 0.5 \\
\hline Water & $\mathbf{C}(\mathbf{1 s}) \%$ & $\mathbf{O ( 1 s ) \%}$ & $\mathbf{F e \%}$ & $\mathbf{C r \%}$ & $\mathbf{N i} \%$ & $\mathbf{M o}(\mathbf{3 d}) \%$ \\
\hline $\mathbf{2 p}$ & 44.6 & 39.4 & 10.9 & 2.6 & 1.8 & 0.7 \\
$\mathbf{3 p}$ & 43.2 & 38.2 & 11.3 & 2.6 & 4.0 & 0.7 \\
\hline \hline
\end{tabular}


Table III: Corrected concentration and related enrichment factors derived from the survey scans and enrichment factors. Cont. d. is the thickness of the contamination layer.

\begin{tabular}{l|llllll}
\hline \hline Air & Fe & $\mathbf{C r}$ & $\mathbf{N i}$ & $\mathbf{M o}(\mathbf{3 d})$ & $\mathbf{O}(\mathbf{1 s})$ & Cont. d. (nm) \\
\hline $\mathbf{2 p \%}$ & 33.5 & 3.7 & 2.4 & 0.6 & 59.8 & 0.4 \\
$\mathbf{3 p \%}$ & 22.9 & 4.9 & 2.5 & 0.6 & 69.0 & \\
$\mathbf{F}$ 2p & 1.21 & 0.46 & 0.61 & 1.20 & & \\
F3p & 1.08 & 0.80 & 0.82 & 1.18 & & \\
\hline Water & Fe & $\mathbf{C r}$ & $\mathbf{N i}$ & $\mathbf{M o}(\mathbf{3 d})$ & $\mathbf{O}(\mathbf{1 s})$ & Cont. d. (nm) \\
\hline 2p\% & 20.4 & 4.7 & 3.0 & 1.2 & 70.7 & 1.2 \\
$\mathbf{3 p \%}$ & 20.7 & 4.6 & 6.6 & 1.2 & 66.9 & \\
$\mathbf{F}$ 2p & 1.08 & 0.80 & 1.07 & 2.40 & & \\
F3p & 0.88 & 0.70 & 2.22 & 2.25 & & \\
\hline \hline
\end{tabular}

Table IV: Original concentrations and corrected concentrations of the elements in air and water exposed steel obtained by XPS at an angle of 51 degrees.

\begin{tabular}{|c|c|c|c|c|c|c|c|c|}
\hline Air & $\mathrm{Fe}(0)$ & $\mathbf{F e}($ III) & $\operatorname{Cr}(0)$ & $\mathrm{Cr}(\mathrm{III})$ & $\mathbf{O}_{2}^{-}$ & $\mathrm{OH}^{-}$ & $\mathrm{H}_{2} \mathrm{O}$ & C \\
\hline Original & 2.1 & 16.9 & 0.4 & 3.3 & 44.3 & 10.8 & 1.7 & 18.5 \\
\hline Corrected & 2.5 & 21.0 & 0.5 & 4.0 & 54.2 & 13.2 & 4.5 & \\
\hline Water & $\mathbf{F e}(0)$ & $\mathrm{Fe}($ III) & $\operatorname{Cr}(0)$ & $\mathrm{Cr}$ (III) & $\mathrm{O}_{2}^{-}$ & $\mathrm{OH}^{-}$ & $\mathrm{H}_{2} \mathrm{O}$ & $\mathrm{C}$ \\
\hline
\end{tabular}




\begin{tabular}{l|llllllll}
\hline Original & 1.5 & 10.2 & 0.4 & 2.9 & 28.6 & 12.6 & 7.7 & 36.1 \\
Corrected & 2.4 & 16.4 & 0.6 & 4.3 & 44.6 & 19.6 & 12.0 & \\
& & & & & & & & \\
\hline \hline
\end{tabular}

Table V: B1 values for Fe and Cr collapsed peak for air and water exposed stainless steel

\begin{tabular}{l|ccc}
\hline \hline B1 & $\mathbf{F e}(\mathbf{0}) / \mathbf{C r}(\mathbf{0})$ & $\mathbf{F e}($ III) & $\mathbf{C r}($ III) \\
\hline Air exposed & $2.79 \times 10^{-3}$ & $-2.12 \times 10^{-4}$ & $-1.36 \times 10^{-4}$ \\
Water exposed & $1.00 \times 10^{-2}$ & $-2.95 \times 10^{-4}$ & $-1.14 \times 10^{-3}$ \\
& & & \\
\hline \hline
\end{tabular}

Table VI: Corrected oxide thickess considering Fe and $\mathrm{Cr}$ peaks for the air and the water exposed samples compared the thickness obtained by $2 \mathrm{p}$ and $3 \mathrm{p}$ peaks from the survey scan.

\begin{tabular}{l|lll}
\hline \hline Oxide & Air & Water & Air From survey \\
\hline $\mathbf{F e}$ & $1.8 \mathrm{~nm}$ & $2.1 \mathrm{~nm}$ & $2.2 \mathrm{~nm}$ \\
$\mathbf{C r}$ & $1.9 \mathrm{~nm}$ & $1.4 \mathrm{~nm}$ & $2.4 \mathrm{~nm}$ \\
Oxide Thickness & $1.85( \pm 0.05) \mathrm{nm}$ & $1.75( \pm 0.35) \mathrm{nm}$ & $2.3( \pm 0.1) \mathrm{nm}$ \\
\hline \hline
\end{tabular}




\section{Figures captions}

Figure 1: XPS survey spectrum of air exposed stainless steel.

Figure 2: XPS survey spectrum of water exposed stainless steel.

Figure 3: The contribution of signal to the XPS analysis using data for iron. The interface position is that obtained in air.

Figure 4: (Color Online) Data obtained from the survey scan after air exposure: composition plotted against depth for $2 p$ and $3 p$ peaks respectively. The points of intersection with the composition of the metal phase are marked by a cross.

Figure 5: Fe2p high resolution fitted peaks for a) air exposed steel and b) water exposed steel.

Figure 6: $\mathrm{Cr} 2 \mathrm{p}$ high resolution fitted peaks for a) air exposed steel and b) water exposed steel.

Figure 7: O1s high resolution fitted peaks for a) air exposed steel and b) water exposed steel.

Figure 8: C1s high resolution fitted peaks for a) air exposed steel and b) water exposed steel.

Figure 9: (Color Online) XPS angular profile of a) air exposed steel and b) water exposed steel.

Figure 10: $\mathrm{O} 1 \mathrm{~s}$ high resolution spectra for a) air exposed $25^{\circ}$, b) air exposed $74^{\circ}, \mathrm{c}$ ) water exposed $25^{\circ}$ and d) water exposed $74^{\circ}$, steel.

Figure 11: SIMS positive spectrum of a) air exposed steel and b) water exposed steel.

Figure 12: (Color Online) SIMS Depth profile of the ions $\mathrm{FeO}^{+}$and $\mathrm{CrO}^{+}$for a) air exposed and b) water exposed steel.

Figure 13: (Color Online) Depth profile of the ions a) $\mathrm{CrO}^{+}, \mathrm{CrOH}^{+}, \mathrm{CrOH}_{2} \mathrm{O}^{+}$and b) $\mathrm{FeO}^{+}$, $\mathrm{FeOH}^{+}, \mathrm{FeOH}_{2} \mathrm{O}^{+}$for air exposed steel.

Figure 14: Mo3d high resolution spectrum for air exposed steel. 